\title{
Metabolism of $\alpha$-linolenic acid during incubations with strained bovine rumen contents: products and mechanisms
}

\author{
Anne M. Honkanen ${ }^{1}$, Heidi Leskinen ${ }^{1}$, Vesa Toivonen ${ }^{1}$, Nest McKain ${ }^{2}$, R. John Wallace ${ }^{2}$ \\ and Kevin J. Shingfield ${ }^{1,3 *}$ \\ ${ }^{1}$ Nutritional Physiology, Green Technology, Natural Resources Institute Finland (Luke), FI-31600 Jokioinen, Finland \\ ${ }^{2}$ Rowett Institute of Nutrition and Health, University of Aberdeen, Bucksburn, Aberdeen AB21 9SB, UK \\ ${ }^{3}$ Institute of Biological Environmental and Rural Sciences, Aberystwyth University, Aberystwyth SY23 3FL, UK \\ (Submitted 17 September 2015 - Final revision received 1 February 2016 - Accepted 9 March 2016 - First published online 18 April 2016)
}

\section{Abstract}

Description of $\alpha$-linolenic acid (cis-9,cis-12,cis-15-18:3, ALA) metabolism in the rumen is incomplete. Ruminal digesta samples were incubated with ALA and buffer containing water or deuterium oxide to investigate the products and mechanisms of ALA biohydrogenation. Geometric $\Delta 9,11,15-18: 3$ isomers were the main intermediates formed from ALA. An increase in the $n+1$ isotopomers of $\Delta 9,11,15-18: 3$ was due to ${ }^{2} \mathrm{H}$ labelling at C-13. Isomers of $\Delta 9,11,13-18: 3$, cis-7,cis-12,cis-15-18:3 and cis-8,cis-12,cis-15-18:3 were also formed. No increase in $n+1$ isotopomers of $\Delta 7,12,15-18: 3$ or $\Delta 8,12,15-18: 3$ was detected. Enrichment in $n+2$ isotopomers of $18: 2$ products indicated that ALA metabolism continued via the reduction of $18: 3$ intermediates. Isomers of $\Delta 9,11,15-18: 3$ were reduced to $\Delta 11,15-18: 2$ labelled at C-9 and C-13. ALA resulted in the formation of $\Delta 11,13-18: 2$ and $\Delta 12,14-18: 2$ containing multiple ${ }^{2} \mathrm{H}$ labels. Enrichment of the $n+3$ isotopomer of $\Delta 12,15-18: 2$ was also detected. Metabolism of ALA during incubations with rumen contents occurs by one of three distinct pathways. Formation of $\Delta 9,11,15-18: 3$ appears to be initiated by $\mathrm{H}$ abstraction on $\mathrm{C}-13$. Octadecatrienoic intermediates containing cis-12 and cis-15 double bonds are formed without an apparent $\mathrm{H}$ exchange with water. Labelling of $\Delta 9,11,13-18: 3$ was inconclusive, suggesting formation by an alternative mechanism. These findings explain the appearance of several bioactive fatty acids in muscle and milk that influence the nutritional value of ruminant-derived foods.

\section{Key words: Biohydrogenation: Conjugated linoleic acid: Conjugated linolenic acid: Linolenic acid: Rumen bacteria}

Clinical, biomedical and in vitro studies have provided evidence that conjugated 18-C fatty acids (FA) including isomers of conjugated linoleic acid (CLA) exhibit potential anti-inflammatory, immuno-modulatory, anti-obesity and anti-carcinogenic activities as well as improve biomarkers of cardiovascular health ${ }^{(1,2)}$. Isomers of conjugated linolenic acid (CLN) containing a conjugated diene double-bond system also have similar biological effects $^{(3,4)}$ with potential as therapeutics for regulating blood glucose and body composition in humans ${ }^{(5)}$. Recent studies in experimental animal models or in vitro have also indicated that isomers of CLN containing a conjugated triene system have anti-carcinogenic and anti-lipogenic activity and may influence immune function ${ }^{(6)}$. A more complete understanding of the mechanisms responsible for the formation of CLN and CLA isomers from $\alpha$-linolenic acid (cis-9,cis-12,cis-15-18:3, ALA) is essential for the synthesis of these compounds in amounts required for the prevention of chronic human diseases or establishing biological activity in a range of mammalian species.
Ruminant fat is relatively abundant in CLA and CLN isomers containing a conjugated diene arrangement of double bonds ${ }^{(7-9)}$, but only trace amounts of CLN isomers containing a conjugated triene double-bond system, which are typically found in certain plant seeds including pomegranate, tung, bitter gourd, catalpa and pot marigold ${ }^{(10)}$. In vitro studies have demonstrated that isomers of CLN trienes, prepared by alkaline treatment, have higher cytotoxic activity during incubations with human tumour cells than their non-conjugated counterparts or CLA isomers ${ }^{(11)}$.

Meat and milk from ruminants are the principal source of CLA in the human diet, with cis-9,trans-11 as the major isomer ${ }^{(12,13)}$. Ruminant foods also contain a wide range of CLA isomers with double bonds located from $\Delta 7,9$ to $\Delta 12,14$ and isomers of $\Delta 9,11,15-$ CLN $^{(7-9)}$. Geometric isomers of $\Delta 9,11$-CLA and $\Delta 10,12-C L A$ are formed during the initial isomerisation of linoleic acid (cis-9,cis-12-18:2, LA) in the rumen ${ }^{(14-16)}$. However, other CLA isomers accumulate in the rumen of cattle fed diets rich in ALA $^{(17-19)}$. Metabolism of ALA in the rumen is thought to involve

Abbreviations: ALA, $\alpha$-linolenic acid; CLA, conjugated linoleic acid; CLN, conjugated linolenic acid; $\mathrm{D}_{2} \mathrm{O}$, deuterium oxide; DMOX, 4,4-dimethyloxazoline. FA, fatty acid; FAME, fatty acid methyl ester; LA, linoleic acid; MPE, moles per cent excess

* Corresponding author: K. J. Shingfield, email kes14@aber.ac.uk 
an initial isomerisation to yield cis-9,trans-11,cis-15-CLN, which is sequentially reduced to trans-11,cis-15-18:2 and trans-11-18:1 with $18: 0$ as an end product ${ }^{(20-22)}$. Historical studies of ruminal ALA biohydrogenation do not consider isomers of CLA as intermediates. However, alternative pathways of ALA biohydrogenation, involving the formation of cis-9,trans-11,trans-15-CLN ${ }^{(9)}$, trans-9,trans-11,cis-15-CLN ${ }^{(23)}$, cis-9,trans-13,cis-15-CLN ${ }^{(24)}$ and trans-10,cis-12, cis-15-CLN ${ }^{(25)}$, have been proposed but not proven. Incubations of ${ }^{13} \mathrm{C}$-labelled ALA with bovine rumen contents were reported to result in the accumulation of fourteen uncharacterised $18: 3$ intermediates $^{(26)}$, highlighting the complexity of ruminal ALA biohydrogenation.

Recent studies have characterised a range of intermediates formed during the incubation of ALA with ovine or bovine rumen contents ${ }^{(23,26,27)}$, but none has provided unambigious evidence on the biochemical pathways responsible. The present study investigated the products formed and possible mechanisms involved in the initial stages of ALA biohydrogenation by rumen microbiota based on an examination of the incorporation of ${ }^{2} \mathrm{H}$ in $\mathrm{FA}$ intermediates formed during incubations of ALA with bovine rumen fluid diluted with water or deuterium oxide $\left(\mathrm{D}_{2} \mathrm{O}\right)$.

\section{Methods \\ Collection of rumen contents}

All experimental procedures involving animals were approved by the National Animal Ethics Committee (Hämeenlinna, Finland), in accordance with the guidelines outlined in the European Community Council Directive 86/609/EEC ${ }^{(28)}$. Four multiparous Finnish Ayrshire cows of mean 253 (SD 11.3) d in lactation and 601 (SD 60) $\mathrm{kg}$ live weight, and fitted with a rumen cannula (i.d. $100 \mathrm{~mm}$; Bar Diamond, Inc.), were used as donors. Each cow received a diet based on a mixture of timothy and meadow fescue grass silage and concentrates (forage: concentrate ratio 60:40, on a DM basis). Concentrates comprised rolled barley $(293 \mathrm{~g} / \mathrm{kg})$, rolled oats $(270 \mathrm{~g} / \mathrm{kg})$, molassed sugar beet pulp $(130 \mathrm{~g} / \mathrm{kg})$, rapeseed expeller $(280 \mathrm{~g} / \mathrm{kg})$ and a proprietary mineral and vitamin premix $(27 \mathrm{~g} / \mathrm{kg}$; Onni-Kivennäinen). Silage and concentrates were offered four times daily at $06.45,13.00,16.00$ and 19.00 hours for $14 \mathrm{~d}$ before starting in vitro incubations. Cows were housed in a barn fitted with individual stalls with continuous access to water, and were milked at 06.30 and 16.45 hours. Samples of rumen contents $(500 \mathrm{ml})$ were collected into plastic bottles from each cow immediately before morning feeding, placed in a $39^{\circ} \mathrm{C}$ water bath and transported to the laboratory.

\section{Incubations with rumen contents}

Batch culture incubations were performed in $100 \mathrm{ml}$ glass flasks $^{(16)}$. Strained rumen contents were diluted 1:2(v/v) with modified McDougall buffer ${ }^{(16)}$ prepared using de-ionised water or $99 \%{ }^{2} \mathrm{H}$-enriched water $\left(\mathrm{D}_{2} \mathrm{O}\right.$; Cambridge Isotope Laboratories, Inc.). A sample of $50 \mathrm{ml}$ of diluted rumen fluid, $400 \mathrm{mg}$ of ground dry hay, $5 \mathrm{mg}$ of ALA (10-1803-30; Larodan Fine Chemicals $\mathrm{AB}$ ) prepared as a suspension in aqueous
Tween $80^{(16)}$ and $5 \mathrm{mg}$ of 19:0 (10-1900-13; Larodan Fine Chemicals $\mathrm{AB})$ dissolved in ethanol $(5 \mathrm{mg} / \mathrm{ml})$ was incubated under carbon dioxide at $39^{\circ} \mathrm{C}$ for $0,1.5,3.0$ and $12 \mathrm{~h}$. Control incubations containing hay, Tween 80 and rumen fluid diluted with de-ionised water were also established over the same time course. At each designated time point, flasks were placed immediately in ice-cold water, and the contents were stored at $-20^{\circ} \mathrm{C}$. Incubations were performed in triplicate with samples of rumen contents from each cow.

\section{Lipid extraction and fatty acid analysis}

Flask contents were freeze-dried for $24 \mathrm{~h}$ at $-90^{\circ} \mathrm{C}$ under a partial pressure of $103 \mathrm{~Pa}$ (Brown Christ Gamma 2; Melsungen AG). In total, $200 \mathrm{mg}$ of freeze-dried incubation contents were mixed with $0.5 \mathrm{ml}$ of de-ionised water and the $\mathrm{pH}$ was adjusted to $2 \cdot 0$ with $2 \mathrm{~m}$-hydrochloric acid. Lipids were extracted in $4 \mathrm{ml}$ of heptane-isopropanol (3:2, v/v). Extraction was repeated and both organic phases recovered were combined, washed with de-ionised water, dried over $200 \mathrm{mg}$ of sodium sulphate and evaporated to dryness under a constant stream of $\mathrm{N}_{2}$ at $30^{\circ} \mathrm{C}$. Fatty acid methyl esters (FAME) were prepared from total lipids using a two-step base-acid catalysed procedure ${ }^{(29)}$. Samples of FAME were also converted to 4,4-dimethyloxazoline (DMOX) derivatives by incubation overnight with 2-amino-2-methyl-1propanol under an $\mathrm{N}_{2}$ atmosphere at $170^{\circ} \mathrm{C}^{(29)}$.

FAME were quantified using a GC (model 6890; Hewlett-Packard) equipped with a flame-ionisation detector and a $100-\mathrm{m}$ fused silica capillary column (i.d. $0.25 \mathrm{~mm}$ ) coated with a $0 \cdot 2-\mu \mathrm{m}$ film of cyanopropyl polysiloxane (CP-SIL 88; Agilent Technologies Inc.). The total FAME profile in a $2-\mu \mathrm{l}$ sample at a split ratio of 1:50 was determined using a temperature gradient programme ${ }^{(30)}$, and $\mathrm{H}_{2}$ as a carrier gas operated at $206.8 \mathrm{kPa}$ for $50 \mathrm{~min}$, which was increased at a rate of $34.5 \mathrm{kPa} / \mathrm{min}$ to a final pressure of $310.3 \mathrm{kPa}$, that was maintained for a further $7 \mathrm{~min}$. The nominal initial flow rate was $2 \cdot 1 \mathrm{ml} / \mathrm{min}$. FAME and DMOX derivatives were analysed by GCMS using a GC equipped with a quadrupole selective mass detector (model 5973N; Agilent Technologies Inc.), operated at $230^{\circ} \mathrm{C}$ in the positive electron ionisation mode using an ionisation voltage of $70 \mathrm{eV}$. Chromatography was performed using the same temperature gradient and column type used for GC analysis of FAME and helium as the carrier gas ${ }^{(29)}$. The analysis was repeated to separate methyl esters of trans-10,cis-15-18:2 and trans-11,cis-15-18:2 using an alternative 100-m column coated with a highly polar ionic liquid SLB-IL111 column $(100 \mathrm{~m} \times 0.25 \mathrm{~mm}$ i.d., $\quad 0.2-\mu \mathrm{m}$ film thickness; SigmaAldrich $)^{(31,32)}$. Helium was used as the carrier gas, operated at a nominal initial flow rate of $1.0 \mathrm{ml} / \mathrm{min}$ at a constant pressure of $264.8 \mathrm{kPa}$ with a temperature programme as follows: initial oven temperature was maintained at $168^{\circ} \mathrm{C}$ for $30 \mathrm{~min}$, increased at $1^{\circ} \mathrm{C} / \mathrm{min}$ to $200^{\circ} \mathrm{C}$ and maintained at $200^{\circ} \mathrm{C}$ temperature for $10 \mathrm{~min}$. The distribution of CLA and CLN isomers was determined by HPLC (model 1090; HewlettPackard) using four silver-impregnated silica columns (ChromSpher 5 Lipids, $250 \times 4.6 \mathrm{~mm}$; 5 - $\mu \mathrm{m}$ particle size; Agilent Technologies Inc.) coupled in series. Methyl esters of CLA or CLN were separated under isocratic conditions at $22^{\circ} \mathrm{C}$ using 
$0.1 \%$ or $0.2 \%(\mathrm{v} / \mathrm{v})$ acetonitrile in heptane, respectively, at a flow rate of $1 \mathrm{ml} / \mathrm{min}$ and monitoring column effluent at 233 and $268 \mathrm{~nm}^{(30)}$. Isomers were identified based on retention time comparisons with methyl ester standards containing a mixture of CLA isomers (Sigma-Aldrich), or geometric isomers of 8,10,12-CLN and 9,11,13-CLN (Larodan Fine Chemicals AB).

FA were identified based on GC-MS analysis of FAME and DMOX derivatives and interpretation of mass spectra according to published guidelines ${ }^{(33,34)}$. For most products, the deduced FA structure was verified by comparison with an online reference spectra library ${ }^{(35)}$. Double-bond geometry was deduced based on relative retention times and known elution order for a mixture of geometric $\Delta 9,12-18: 2$ and $\Delta 9,12,15-18: 3$ methyl esters (Sigma-Aldrich) during GC analysis ${ }^{(36)}$. The double-bond geometry of 9,11,15-18:3 isomers was inferred based on the elution order reported in the literature ${ }^{(8,9,23)}$.

Enrichment of $m / z \quad n+1, n+2$ and $n+3$ isotopomers (molecular ion $+1,+2$ and +3 , respectively) was determined by GC-MS analysis of FAME. Enrichment in water was determined by gas isotope ratio MS using a VG SIRA 10 (VG Isotech) gas isotope ratio MS fitted with a split flight tube and $\mathrm{H} /{ }^{2} \mathrm{H}$ collector ${ }^{(15)}$. Corrections for $\mathrm{H}^{3+}$ were made using dedicated software at the time of measurement. The position of ${ }^{2} \mathrm{H}$ labelling of incubation products was determined by GC-MS analysis of DMOX derivatives.

\section{Data analysis}

Amounts of FA in incubation flasks were analysed by ANOVA for repeated measures with a statistical model that included the fixed effect of incubation time, treatments (control and test incubations containing added ALA with de-ionised water or $\left.\mathrm{D}_{2} \mathrm{O}\right)$ and their interaction and random effect of replicate nested within cow assuming a compound symmetry covariance structure using the MIXED procedure of SAS (version 9.2; SAS Institute, Inc.). Denominator df were calculated using the Kenward-Rogers method. The same statistical model was used to compare the abundance of $n+1, n+2$ and $n+3$ isotopomers of products formed during incubations of ALA with $\mathrm{D}_{2} \mathrm{O}$ or deionised water (natural enrichment). Enrichment of $n+1, n+2$ and $n+3$ isotopomers was calculated from the $m / z$ ratios at $n$, $n+1, n+2, n+3$ and $n+4$ by deconvolution ${ }^{(15,37)}$. Changes in the enrichment of $n+1, n+2$ and $n+3$ isotopomers of products formed during $0,1.5,3.0$ and $12 \mathrm{~h}$ of incubation of ALA with $\mathrm{D}_{2} \mathrm{O}$ were analysed by ANOVA for repeated measures with a statistical model that included the fixed effect of incubation time and random effect of replicate nested within cow assuming a compound symmetry covariance structure and calculation of denominator df by the Kenward-Rogers method. Fixed effects were considered significant at $P<0 \cdot 05$. Least square means with pooled standard errors are reported.

\section{Results}

\section{Metabolism of $\alpha$-linolenic acid during incubations with strained rumen contents}

Strained ruminal digesta samples collected from four lactating cows were diluted with buffer containing de-ionised water or
$\mathrm{D}_{2} \mathrm{O}$ and incubated with ALA under anaerobic conditions for up to $12 \mathrm{~h}$. Concentrations of added ALA declined rapidly (Fig. 1), resulting in the appearance $(P<0.05)$ of $18: 3$ and $18: 2$ intermediates relative to control incubations (Fig. 2). The relative disappearance of ALA (Fig. 1) and formation of intermediates were similar (Fig. 2), but not identical during incubations of ALA with rumen fluid diluted with water or $\mathrm{D}_{2} \mathrm{O}$.

\section{Formation of octadecatrienoic acids during incubation of $\alpha$-linolenic acid with strained rumen contents}

Addition of ALA increased $(P<0.05)$ the formation of CLN isomers compared with hay and rumen fluid alone (Table 1). Cis-9,trans-11,cis-15-18:3 was the most abundant CLN isomer in all incubations, but smaller amounts of trans-9,trans-11,cis-15-CLN were also detected (Table 1). Cis-9,trans-11,Cis-15-CLN was formed in the greatest quantity immediately after the addition of ALA to strained rumen contents, but disappeared from flask contents over the course of $12 \mathrm{~h}$ incubations. Formation of trans-9,trans-11,cis-15-CLN from ALA was greatest during the first 1.5-3 h of incubation, but the amounts declined thereafter. Small amounts of trans-9,trans-11,cis-13-CLN were also formed (Table 1). Addition of ALA with rumen contents increased $(P<0.05)$ the appearance of cis-7,cis-12,cis-15-18:3, cis-8,cis-12, cis-15-18:3 and trans-8,cis-12,cis-15-18:3 in flask contents, with the highest amounts detected after 1.5 and $3 \mathrm{~h}$ of incubation.

All incubation flasks contained $\Delta 10,12,15$-CLN. Addition of ALA increased $(P<0.05) \Delta 10,12,15$-CLN formation during $1.5 \mathrm{~h}$ of incubation with rumen contents diluted in water (Table 1). However, formation of 10,12,15-CLN between 0 and $3 \mathrm{~h}$ did not differ $(P>0.05)$ between incubations of ALA with $\mathrm{D}_{2} \mathrm{O}$ and the control. After $12 \mathrm{~h}$, the amounts of $\Delta 10,12,15$-CLN were lower $(P<0.05)$ for incubations containing $\mathrm{D}_{2} \mathrm{O}$ (Table 1$)$.

Mass spectra of methyl esters prepared from flask contents over the course of 0 to $12 \mathrm{~h}$ incubations of ALA with $\mathrm{D}_{2} \mathrm{O}$

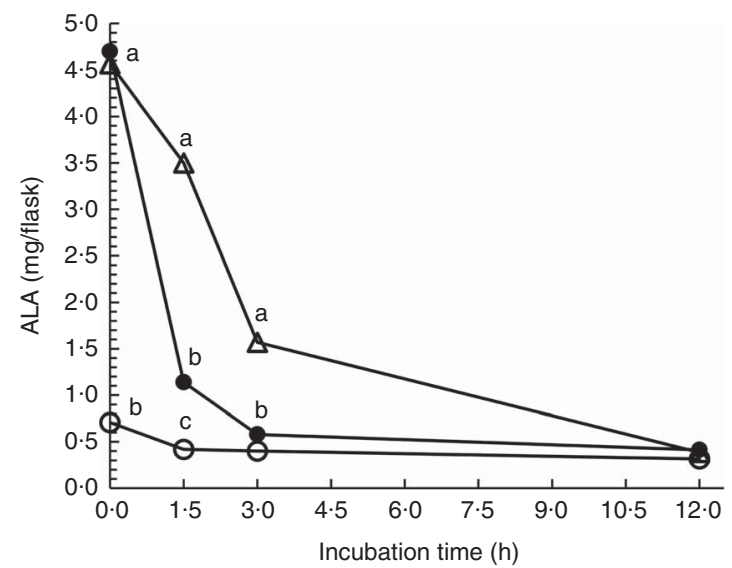

Fig. 1. Disappearance of $a$-linolenic acid (ALA) during 0 to $12 \mathrm{~h}$ incubations of ground hay with strained rumen fluid diluted in de-ionised water $(O)$, rumen fluid diluted in de-ionised water and $5 \mathrm{mg}$ of added ALA (O) or rumen fluid diluted in 56.6 (SEM 1.33) \% moles per cent excess (MPE) deuterium oxide and $5 \mathrm{mg}$ of added ALA $(\triangle)$. Rumen contents were collected from four cows and incubated at $39^{\circ} \mathrm{C}$ under carbon dioxide. Each point represents the least square mean of $n 12$ measurements (pooled SEM $0.083 \mathrm{mg} /$ flask). ${ }^{\mathrm{a}, \mathrm{b}, \mathrm{c}}$ Mean values for each incubation time with unlike letters were significantly different $(P<0.05)$. 
(a)

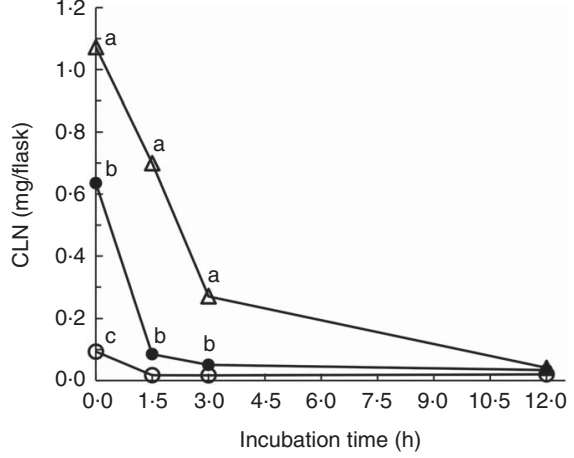

(c)

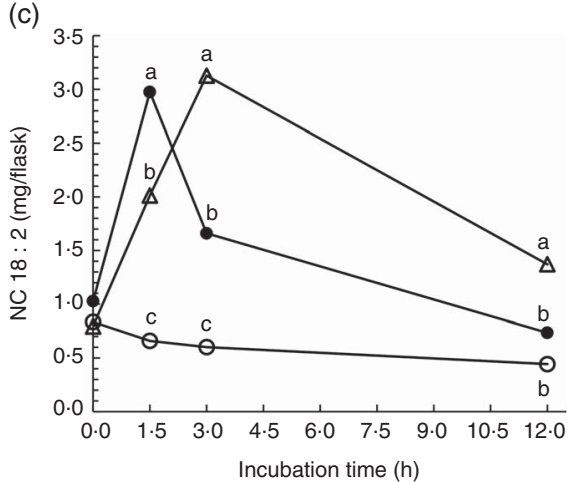

(b)

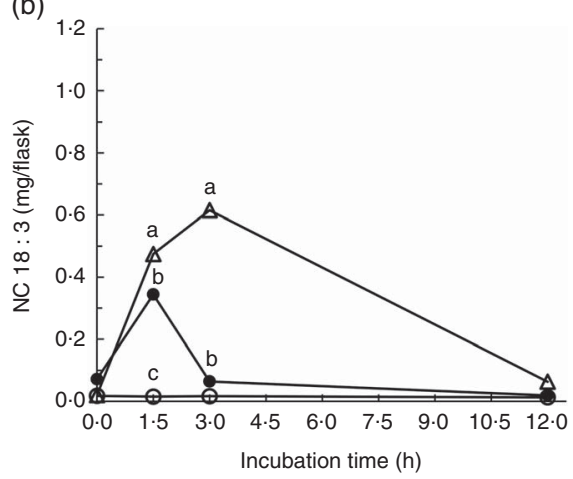

(d)

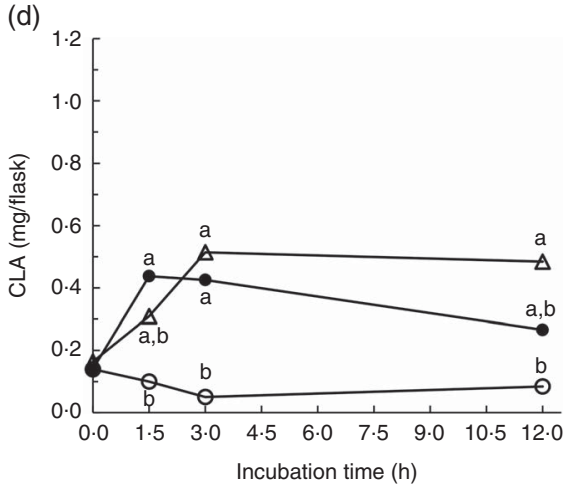

Fig. 2. Formation of (a) total conjugated linolenic acid (CLN), (b) non-conjugated 18:3 (NC 18:3), (c) non-conjugated 18:2 (NC 18:2) and (d) conjugated linoleic acid $(C L A)$ during 0 to $12 \mathrm{~h}$ incubations of ground hay with strained rumen fluid diluted in de-ionised water $(O)$, rumen fluid diluted in de-ionised water and $5 \mathrm{mg}$ of added $a$-linolenic acid (ALA) (O) or rumen fluid diluted in $56.6 \pm 1.33 \%$ moles per cent excess deuterium oxide and $5 \mathrm{mg}$ of added ALA ( $\triangle$ ). Rumen contents were collected from four cows and incubated at $39^{\circ} \mathrm{C}$ under carbon dioxide. Each point represents the mean of $n 12$ measurements (sEM $0.026,0.020,0.098$ and $0.043 \mathrm{mg} /$ flask for total CLN, NC 18:3, NC 18:2 and CLA, respectively). ${ }^{\text {a,b,c }}$ Mean values for each incubation time with unlike letters were significantly different $(P<0.05)$.

indicated that geometric isomers of $\Delta 9,11,15$-CLN contained a single ${ }^{2} \mathrm{H}$ label. Independent analysis of the enrichment in water allowed for the comparison of the ratio of moles per cent excess (MPE) in FAME with the MPE of water. All samples of water had a similar enrichment of 56.6 (SE 1.33)\%. Calculated labelling (MPE intermediate/MPE water) averaged 0.79 and 0.83 for cis-9,trans-11,cis-15-18:3 and trans-9,trans-11,cis-15-CLN, respectively (Table 2). The mass spectrum of the DMOX derivative of cis-9,trans-11,cis-15-CLN formed during incubations of ALA with $\mathrm{D}_{2} \mathrm{O}$ containing buffer indicated enrichment of ion fragments from the molecular ion to $m / z 262$ (Fig. 3). The occurrence of ion fragment isotopomers with $m / z<262$ was comparable with the natural abundance of $22 \cdot 2 \%$. Analysis of ion fragments located the incorporation of ${ }^{2} \mathrm{H}$ on $\mathrm{C}-13$ of the FA moiety. The mass spectrum of trans-9,trans-11,cis-15-CLN indicated a similar pattern of enrichment with labelling on C-13 (data not presented).

Labelling (MPE sample/MPE water) of $n+1$ isotopomers of trans-9,trans-11,cis-13-CLN increased $(P<0.001)$ during $12 \mathrm{~h}$ incubations with ALA (Table 2). Abundance of $n+1$ isotopomers of trans-9,trans-11, cis-13-CLN formed during 1.5, 3 and $12 \mathrm{~h}$ of incubation of ALA with $\mathrm{D}_{2} \mathrm{O}$ was higher $(P<0 \cdot 001)$ compared with natural abundance (average 35.7 and $21.8 \%$, respectively). Enrichment of $n+1$ isotopomers of cis-7,cis-12, cis-15-18:3, cis-8,cis-12,cis-15-18:3 and trans-8,cis-12,cis-15$18: 3$ formed after 1.5 and $3 \mathrm{~h}$ of incubation with ALA averaged
$0 \cdot 01,-0 \cdot 19$ and $0 \cdot 01$, respectively (Table 2 ). Relative abundance of $n+1$ isotopomers for $\Delta 7,12,15-18: 3$ and $\Delta 8,12,15-18: 3$ formed in the presence of $\mathrm{D}_{2} \mathrm{O}$ did not differ $(P>0.05)$ from natural enrichment. Furthermore, the mass spectra of the DMOX derivatives of cis-7,cis-12,cis-15-18:3 (online Supplementary Fig. S1) and cis-8,cis-12,cis-15-18:3 (online Supplementary Fig. S2) provided no evidence of ${ }^{2} \mathrm{H}$ labelling.

The $\Delta 10,12,15-C L N$ isomer eluted immediately after cis-9, trans-11,cis-15-CLN during GC-MS analysis. It was not possible to obtain reliable mass spectra for the methyl ester or DMOX derivative of $\triangle 10,12,15$-CLN formed during 0 to $12 \mathrm{~h}$ incubations of ALA with $\mathrm{D}_{2} \mathrm{O}$. Calculated labelling at $n+1$ of $\Delta 10,12,15$-CLN formed after 1.5 and $3 \mathrm{~h}$ incubations averaged $0 \cdot 28$ (Table 2). Relative abundance of $n+1$ isotopomers of $\Delta 10,12,15$-CLN was higher compared with natural enrichment $(P<0.05)$, but the position of the ${ }^{2} \mathrm{H}$ label could not be located. Concentrations of 10,12,15-CLN were too low to allow the MPE at $n+2$ to be estimated accurately.

\section{Formation of octadecadienoic acids during incubation of $\alpha$-linolenic acid with strained rumen contents}

Cis-12,cis-15-18:2 and trans-11,cis-15-18:2 represented the major non-conjugated 18:2 products formed during incubations with ALA, with smaller amounts of trans-10,cis-15-18:2 
Table 1. Amounts of $18: 3$ intermediates formed during 0 to $12 \mathrm{~h}$ incubations of $a$-linolenic acid with rumen contents diluted in buffer prepared using de-ionised $\mathrm{H}_{2} \mathrm{O}$ or deuterium oxide $\left(\mathrm{D}_{2} \mathrm{O}\right)^{\star}$ (Mean values with their pooled standard errors)

\begin{tabular}{|c|c|c|c|c|c|c|c|c|c|c|c|c|c|c|c|c|}
\hline \multirow[b]{3}{*}{ Treatments... } & \multicolumn{12}{|c|}{ Incubation time (h) } & \multirow[b]{3}{*}{ SEM $¥$} & \multirow{2}{*}{\multicolumn{3}{|c|}{$P \dagger$}} \\
\hline & \multicolumn{3}{|c|}{$\mathrm{Oh}$} & \multicolumn{3}{|c|}{$1.5 \mathrm{~h}$} & \multicolumn{3}{|c|}{$3 \mathrm{~h}$} & \multicolumn{3}{|c|}{$12 \mathrm{~h}$} & & & & \\
\hline & CON & $\mathrm{H}_{2} \mathrm{O}$ & $\mathrm{D}_{2} \mathrm{O}$ & $\mathrm{CON}$ & $\mathrm{H}_{2} \mathrm{O}$ & $\mathrm{D}_{2} \mathrm{O}$ & CON & $\mathrm{H}_{2} \mathrm{O}$ & $\mathrm{D}_{2} \mathrm{O}$ & CON & $\mathrm{H}_{2} \mathrm{O}$ & $\mathrm{D}_{2} \mathrm{O}$ & & Time & Treatment & Time $\times$ treatment \\
\hline \multicolumn{17}{|l|}{ Amount ( $\mu \mathrm{g} /$ flask) } \\
\hline cis-9, trans- 11, cis- 15 & $83 \cdot 1^{\mathrm{C}}$ & $612^{b}$ & $1040^{\mathrm{a}}$ & $4 \cdot 21^{\mathrm{b}}$ & $32.8^{\mathrm{b}}$ & $648^{a}$ & $4.29^{c}$ & $17 \cdot 5^{a, b}$ & $188^{\mathrm{a}}$ & 4.48 & 7.66 & $15 \cdot 2$ & 25.67 & $<0.001$ & $<0.001$ & $<0.001$ \\
\hline trans -9, trans -11, cis- 15 & 1.31 & 7.38 & 6.33 & $1.23^{\mathrm{b}}$ & $15 \cdot 5^{\mathrm{a}}$ & $24 \cdot 0^{\mathrm{a}}$ & $0.85^{\mathrm{b}}$ & $4.47^{b}$ & $36 \cdot 3^{a}$ & 2.62 & 1.69 & 2.66 & 2.697 & 0.003 & 0.002 & $<0.001$ \\
\hline$\Delta 10,12,15$ & $3 \cdot 20^{\mathrm{b}}$ & $6 \cdot 32^{\mathrm{a}}$ & $5 \cdot 51^{a, b}$ & $4.47^{b}$ & $9 \cdot 04^{\mathrm{a}}$ & $7 \cdot 04^{a, b}$ & 5.89 & 8.02 & 7.81 & $8 \cdot 73^{\mathrm{a}}$ & $9 \cdot 18^{\mathrm{a}}$ & $4 \cdot 19^{b}$ & 0.661 & 0.006 & 0.006 & $<0.001$ \\
\hline trans -9, trans -11, cis -13 & $8 \cdot 22^{b}$ & $15 \cdot 7^{\mathrm{a}, \mathrm{b}}$ & $23 \cdot 3^{\mathrm{a}}$ & $7 \cdot 96^{\mathrm{b}}$ & $23 \cdot 9^{\mathrm{a}}$ & $27 \cdot 2^{a}$ & $6.56^{\mathrm{c}}$ & $19.6^{\mathrm{b}}$ & $37 \cdot 4^{\mathrm{a}}$ & $5 \cdot 26^{\mathrm{b}}$ & $14 \cdot 7^{a, b}$ & $21.6^{\mathrm{a}}$ & $2 \cdot 220$ & 0.010 & $<0.001$ & 0.010 \\
\hline cis-7,cis-12,cis-15 & 1.76 & $24 \cdot 1$ & 2.02 & $3.03^{\mathrm{C}}$ & $99.5^{\mathrm{b}}$ & $155^{\mathrm{a}}$ & $5.05^{\mathrm{b}}$ & $19 \cdot 2^{\mathrm{b}}$ & $185^{\mathrm{a}}$ & 3.43 & 3.44 & 6.08 & 6.770 & $<0.001$ & $<0.001$ & $<0.001$ \\
\hline cis-8, cis-12,cis-15 & $5 \cdot 68^{\mathrm{a}}$ & $28 \cdot 4^{\mathrm{a}}$ & $4.68^{a}$ & $3.95^{\mathrm{b}}$ & $174^{\mathrm{a}}$ & $193^{\mathrm{a}}$ & $3 \cdot 32^{\mathrm{b}}$ & $25 \cdot 8^{\mathrm{b}}$ & $257^{\mathrm{a}}$ & 1.75 & 5.76 & $42 \cdot 1$ & 14.56 & $<0.001$ & $<0.001$ & $<0.001$ \\
\hline trans-8, cis-12,cis-15 & $10.5^{\mathrm{a}}$ & $19 \cdot 3^{\mathrm{a}}$ & $11.6^{\mathrm{a}}$ & $8 \cdot 36^{\mathrm{b}}$ & $70.5^{\mathrm{a}}$ & $60 \cdot 4^{\mathrm{a}}$ & $8 \cdot 26^{\mathrm{b}}$ & $19 \cdot 2^{\mathrm{b}}$ & $78 \cdot 8^{\mathrm{a}}$ & 7.62 & $10 \cdot 0$ & 9.86 & 2.891 & $<0.001$ & $<0.001$ & $<0.001$ \\
\hline
\end{tabular}

a,b,c Mean values within a row for each incubation time with unlike superscript letters were significantly different $(P<0.05)$

* Incubations established in 100 -ml flasks containing $400 \mathrm{ml}$ ground dried hay and $50 \mathrm{ml}$ of diluted rumen fluid maintained at $39^{\circ} \mathrm{C}$ under carbon dioxide containing no additional $\alpha$-linolenic acid (CON) or $5 \mathrm{mg}$ of added $\alpha$-linolenic acid and rumen fluid diluted with de-ionised $\mathrm{H}_{2} \mathrm{O}$ or $\mathrm{D}_{2} \mathrm{O}$.

t Significance due to incubation time, incubation treatment and their interaction.

$\ddagger$ Pooled SEM for $n 36$ measurements.

Table 2. Enrichment of $n+1, n+2$ and $n+3$ isotopomers of $18: 3$ intermediates formed during incubations of $\alpha$-linolenic acid (ALA) with strained rumen contents diluted in ${ }^{2} \mathrm{H}$-containing buffer ${ }^{\star}$ (Mean values with their pooled standard errors)

\begin{tabular}{|c|c|c|c|c|c|c|c|c|c|c|c|c|}
\hline \multirow[b]{3}{*}{ Incubation time (h). } & \multicolumn{10}{|c|}{ Isotopomers } & & \\
\hline & \multicolumn{5}{|c|}{$n+1$} & \multicolumn{5}{|c|}{$n+2$} & \multicolumn{2}{|c|}{$P+$} \\
\hline & 0 & 1.5 & 3 & 12 & SEM $\ddagger$ & 0 & 1.5 & 3 & 12 & SEM $¥$ & $n+1$ & $n+2$ \\
\hline \multicolumn{13}{|l|}{ Fatty acid } \\
\hline cis-9,trans-11, cis-15-18:3 & $0.92^{\mathrm{a}}$ & $0.82^{\mathrm{b}}$ & $0.79^{b}$ & $0.62^{c}$ & 0.010 & $-0.05^{\mathrm{b}}$ & $-0.03^{b}$ & $0.01^{a}$ & $0.02^{\mathrm{a}}$ & 0.019 & $<0.001$ & $<0.001$ \\
\hline trans-9, trans-11, cis-15-18:3 & $0.92^{a}$ & $0.81^{\mathrm{b}}$ & $0.82^{\mathrm{b}}$ & $0.76^{\mathrm{b}}$ & 0.035 & -0.06 & 0.05 & 0.13 & 0.04 & 0.054 & 0.009 & 0.051 \\
\hline$\Delta 10,12,15-18: 3$ & ND & $0.32^{\mathrm{a}}$ & $0.23^{\mathrm{b}}$ & ND & 0.014 & ND & ND & ND & ND & ND & 0.003 & - \\
\hline trans-9, trans-11, cis-13-18:3 & $0 \cdot 10^{\mathrm{d}}$ & $0.14^{\mathrm{C}}$ & $0.20^{\mathrm{b}}$ & $0.34^{a}$ & 0.009 & $-0.09^{b}$ & $-0.09^{b}$ & $-0.08^{b}$ & $-0.05^{a}$ & 0.007 & $<0.001$ & $<0.001$ \\
\hline cis- 7, cis- 12, cis- $15-18: 3$ & ND & $-0.02^{\mathrm{b}}$ & 0.03 & ND & 0.023 & ND & -0.04 & -0.07 & ND & 0.035 & 0.180 & 0.235 \\
\hline cis-8, cis-12, cis-15-18:3 & ND & -0.18 & -0.19 & ND & 0.022 & ND & 0.06 & 0.06 & ND & 0.014 & 0.450 & 0.645 \\
\hline trans-8, cis-12, cis-15-18: 3 & 0.03 & $-0.02^{\mathrm{b}}$ & 0.03 & $0.14^{\mathrm{a}}$ & 0.030 & 0.03 & -0.02 & -0.04 & 0.02 & 0.023 & 0.009 & 0.099 \\
\hline
\end{tabular}

${ }_{\text {a,b,c }}$ Mean values within a row for each incubation time with unlike superscript letters were significantly different $(P<0.05)$.

* Enrichment calculated from the ratio of moles per cent excess (MPE) in the incubation product/MPE in water. Mean $56 \cdot 6$ (SE 1.33)\% MPE enrichment in deuterated water. Natural abundance of $n+1$ and $n+2$ isotopomers was determined for the same products formed during incubations of ALA with strained rumen contents diluted in de-ionised water.

† Significance due to incubation time. 

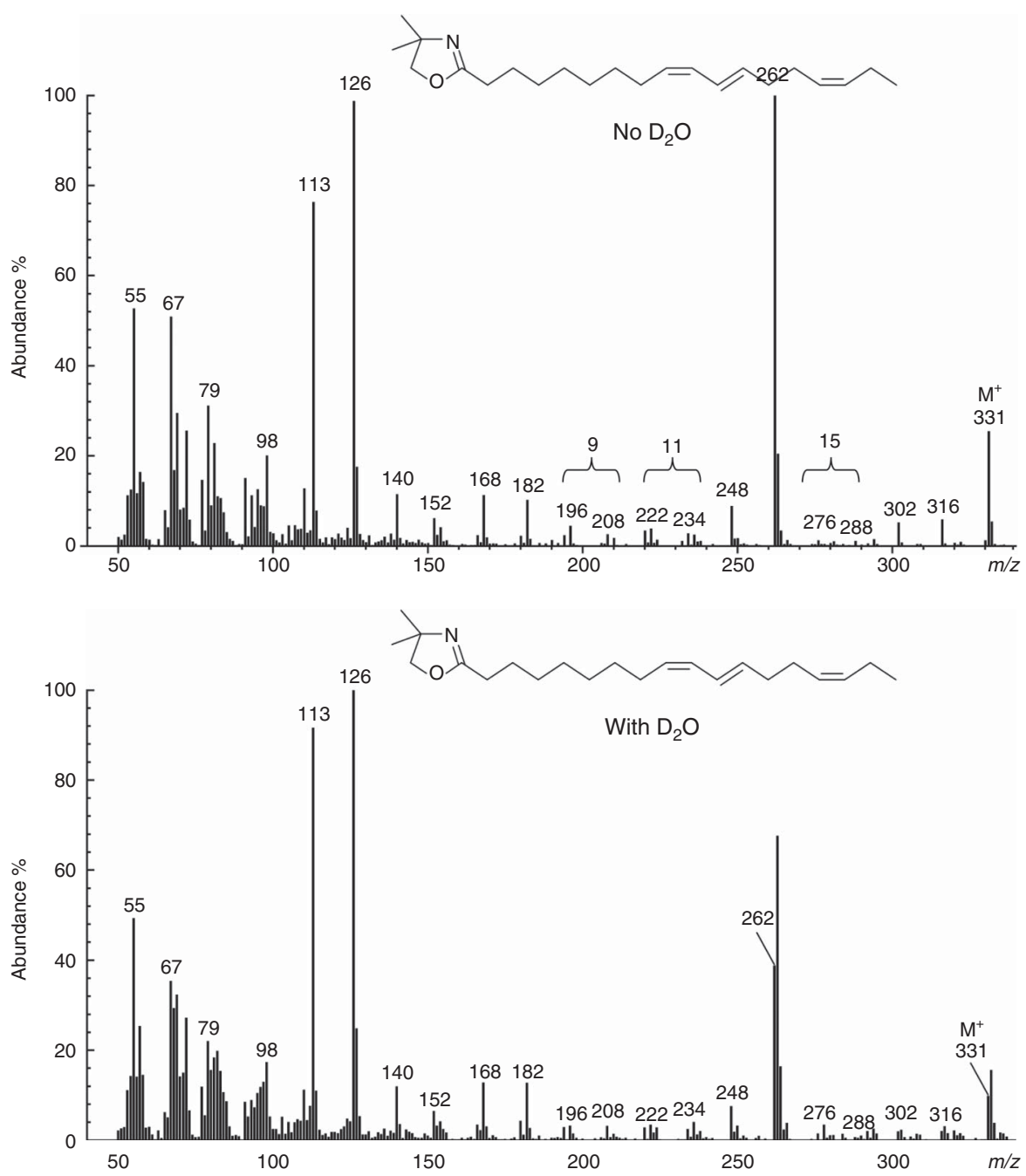

Fig. 3. Mass spectrum of the 4,4-dimethyloxazoline derivative of cis-9, trans-11,cis-15-18:3 formed from a-linolenic acid during incubations with strained rumen contents diluted with buffer prepared using de-ionised water or deuterium oxide. Gaps of 12 atomic mass units between $m / z 196$ and 208,222 and 234 and 276 and 288 located double bonds at $\Delta 9,11$ and 15, respectively. Enrichment of ion fragments at $m / z 262$ and 263 indicate labelling on C-13 of the fatty acid moiety during incubations with ${ }^{2} \mathrm{H}$-containing buffer.

also detected (Table 3 ). Incubation of ALA with rumen contents diluted with water increased $(P<0.05)$ the amount of $c i s-12$, trans-14-CLA, trans-11,cis-13-CLA, trans-11,trans-13-CLA, trans-12,cis-14-CLA, trans-12,trans-14-CLA and trans-13,trans15-CLA in flask contents (Table 3). However, the amounts of CLA products formed differed during incubations of ALA with $\mathrm{D}_{2} \mathrm{O}$ or water. Trans-10,cis-12-CLA and trans-10,trans-12-CLA were detected in all flask contents but the amount of trans-10, trans-12-CLA did not change $(P=0.47)$ over the course of all incubations (Table 3). The amount of trans-10,cis-12-CLA in samples containing added ALA with water or $\mathrm{D}_{2} \mathrm{O}$ decreased $(P<0.05)$ during incubation from 3 to $12 \mathrm{~h}$.

Mass spectra of methyl esters were used to calculate the MPE ratios of $n+1, n+2$ and $n+3$ isotopomers of $18: 2$ products formed during incubations with added ALA (Table 4). Enrichment of $n+1$ isotopomers of cis-12,cis-15-18:2, trans-10,cis-15-18: 2, trans-11,cis-15-18:2, trans-11,cis-13-CLA, trans-11,trans-13-CLA and cis-9,trans-11-CLA from 1.5 to $12 \mathrm{~h}$ incubations averaged $1.13,1.03,1.01,0.89,0.83$ and 0.18 , respectively (Table 4). Labelling at $n+2$ for the same intermediates averaged 0.99, 0.75, 0.74, 0.63, 0.46 and -0.01, respectively. Average enrichment of $n+3$ isotopomers was $0 \cdot 43,0 \cdot 17,0 \cdot 13,0 \cdot 05,0 \cdot 16$ and $<0 \cdot 01$, respectively. For 3 to $12 \mathrm{~h}$ incubations, enrichment of $n+1, n+2$ and $n+3$ isotopomers of trans-12,trans-14-CLA averaged 1.0, 0.91 and $0 \cdot 52$, respectively.

The molecular ion of the DMOX derivative of trans-11,cis-15$18: 2$ formed during incubations of ALA with $\mathrm{D}_{2} \mathrm{O}$ at $m / z 335$ $(n+2)$ confirmed the incorporation of two ${ }^{2} \mathrm{H}$ labels in the FA moiety (Fig. 4). Relative abundances of ion fragments at $\mathrm{m} / \mathrm{z}$ 210 and 211 and at $m / z$ 264, 265 and 266 located the incorporation of a single ${ }^{2} \mathrm{H}$ on $\mathrm{C}-9$ and another on $\mathrm{C}-13$. The mass spectrum of the DMOX derivative of cis-12,cis-15-18:2 formed in the presence of $\mathrm{D}_{2} \mathrm{O}$ indicated a molecular ion at $m / z$ $336(n+3)$, confirming an octadecadienoic acid structure and incorporation of three ${ }^{2} \mathrm{H}$ atoms, but the position of each label could not be determined accurately (online Supplementary Fig. S3). Furthermore, the amounts of trans-10,cis-15-18:2 in 
Table 3. Amounts of $18: 2$ intermediates formed during 0 to $12 \mathrm{~h}$ incubations of $a$-linolenic acid with rumen contents diluted in buffer prepared using de-ionised $\mathrm{H}_{2} \mathrm{O}$ or deuterium oxide $\left(\mathrm{D}_{2} \mathrm{O}\right)^{\star}$ (Mean values with their standard errors)

\begin{tabular}{|c|c|c|c|c|c|c|c|c|c|c|c|c|c|c|c|c|}
\hline \multirow[b]{3}{*}{ Treatments... } & \multicolumn{12}{|c|}{ Incubation time (h) } & \multirow[b]{3}{*}{ SEM $\ddagger$} & \multirow{2}{*}{\multicolumn{3}{|c|}{$P \dagger$}} \\
\hline & \multicolumn{3}{|c|}{$\mathrm{Oh}$} & \multicolumn{3}{|c|}{$1.5 \mathrm{~h}$} & \multicolumn{3}{|c|}{$3 \mathrm{~h}$} & \multicolumn{3}{|c|}{$12 \mathrm{~h}$} & & & & \\
\hline & CON & $\mathrm{H}_{2} \mathrm{O}$ & $\mathrm{D}_{2} \mathrm{O}$ & CON & $\mathrm{H}_{2} \mathrm{O}$ & $\mathrm{D}_{2} \mathrm{O}$ & $\mathrm{CON}$ & $\mathrm{H}_{2} \mathrm{O}$ & $\mathrm{D}_{2} \mathrm{O}$ & CON & $\mathrm{H}_{2} \mathrm{O}$ & $\mathrm{D}_{2} \mathrm{O}$ & & Time & Treatment & Time $\times$ treatment \\
\hline \multicolumn{17}{|l|}{ Amount ( $\mu \mathrm{g} /$ flask) } \\
\hline cis- 12, cis -15 & 9.42 & 21.9 & 3.50 & $18 \cdot 5^{\mathrm{b}}$ & $1300^{\mathrm{a}}$ & $233^{b}$ & $10 \cdot 6^{\mathrm{b}}$ & $507^{\mathrm{a}}$ & $706^{\mathrm{a}}$ & 7.96 & 145 & 244 & $45 \cdot 60$ & $<0.001$ & $<0.001$ & $<0.001$ \\
\hline trans-10,cis-15 & 0.00 & 0.00 & 0.00 & $0.00^{\mathrm{a}}$ & $383^{\mathrm{b}}$ & $0.00^{\mathrm{a}}$ & $0.00^{\mathrm{b}}$ & $174^{\mathrm{a}}$ & $21 \cdot 6^{\mathrm{b}}$ & 0.00 & 51.9 & $8 \cdot 13$ & 18.93 & $<0.001$ & 0.064 & 0.005 \\
\hline trans-11, cis-15 & $97 \cdot 4$ & 192 & $65 \cdot 2$ & $75 \cdot 5^{\mathrm{b}}$ & $835^{\mathrm{a}}$ & $951^{\mathrm{a}}$ & $66.8^{\mathrm{c}}$ & $412^{b}$ & $1450^{\mathrm{a}}$ & $53 \cdot 3^{\mathrm{c}}$ & $150^{\mathrm{b}}$ & $527^{\mathrm{a}}$ & 33.67 & $<0.001$ & $<0.001$ & $<0.001$ \\
\hline cis-9, trans -11 & $78 \cdot 3^{\mathrm{a}}$ & $54 \cdot 5^{\mathrm{b}}$ & $66 \cdot 1^{\mathrm{a}, \mathrm{b}}$ & $19 \cdot 5^{\mathrm{b}}$ & $19 \cdot 4^{\mathrm{b}}$ & $54 \cdot 9^{\mathrm{a}}$ & $16 \cdot 9^{b}$ & $15 \cdot 9^{\mathrm{b}}$ & $37.3^{\mathrm{a}}$ & $12 \cdot 7$ & 11.0 & 10.2 & $3 \cdot 261$ & $<0.001$ & 0.005 & $<0.001$ \\
\hline cis-11, trans -13 & 1.37 & 1.16 & $1 \cdot 72$ & $0.50^{\mathrm{b}}$ & $1.61^{\mathrm{b}}$ & $58.8^{\mathrm{a}}$ & $0.00^{\mathrm{b}}$ & $1.07^{\mathrm{b}}$ & $81 \cdot 2^{\mathrm{a}}$ & $0.00^{b}$ & $0.38^{a, b}$ & $7 \cdot 21^{a}$ & 1.170 & $<0.001$ & $<0.001$ & $<0.001$ \\
\hline cis-12,trans-14 & 0.40 & 0.55 & 0.31 & $1.68^{\mathrm{b}}$ & $26 \cdot 6^{\mathrm{a}}$ & $8.98^{\mathrm{b}}$ & $0.56^{\mathrm{b}}$ & $9.52^{\mathrm{b}}$ & $34.5^{\mathrm{a}}$ & 1.23 & 2.99 & 8.80 & $2 \cdot 805$ & 0.002 & 0.008 & $<0.001$ \\
\hline trans -10, cis -12 & 24.5 & 33.2 & 36.7 & $16 \cdot 3^{\mathrm{b}}$ & $22 \cdot 1^{a, b}$ & $40 \cdot 9^{\mathrm{a}}$ & $6 \cdot 02^{\mathrm{b}}$ & $14 \cdot 9^{\mathrm{a}, \mathrm{b}}$ & $32 \cdot 6^{\mathrm{a}}$ & 11.9 & 6.75 & $12 \cdot 2$ & 4.507 & 0.003 & 0.011 & 0.072 \\
\hline trans -11 , cis- 13 & $12 \cdot 1$ & $13 \cdot \overline{9}$ & 5.53 & $14 \cdot 6^{\mathrm{c}}$ & $37.5^{\mathrm{b}}$ & $61 \cdot 1^{a}$ & $6.49^{c}$ & $24.0^{\mathrm{b}}$ & $85.6^{\mathrm{a}}$ & 14.3 & 13.7 & $12 . \overline{7}$ & 3.409 & $<0.001$ & $<0.001$ & $<0.001$ \\
\hline trans -12, cis- 14 & 1.24 & 1.18 & 0.62 & 3.88 & 47.4 & 1.54 & $1.30^{\mathrm{b}}$ & $118^{\mathrm{a}}$ & $11 \cdot 1^{\mathrm{b}}$ & $2 \cdot 35^{b}$ & $51 \cdot 8^{\mathrm{a}, \mathrm{b}}$ & $96 \cdot 8^{\mathrm{a}}$ & $16 \cdot 46$ & 0.035 & 0.029 & 0.009 \\
\hline trans -10, trans -12 & 4.23 & 5.50 & $6 \cdot 10$ & 5.62 & 7.19 & $8 \cdot 14$ & 2.93 & $5 \cdot 82$ & 9.96 & 5.83 & 5.39 & 6.51 & 1.368 & 0.468 & 0.064 & 0.333 \\
\hline trans -11 , trans -13 & 7.40 & $19 \cdot 1$ & 6.35 & $19 \cdot 1^{\mathrm{b}}$ & $223^{a}$ & $55 \cdot 9^{\mathrm{b}}$ & $7.68^{\mathrm{b}}$ & $132^{a, b}$ & $209^{a}$ & $16 \cdot 3^{\mathrm{b}}$ & $90 \cdot 3^{\mathrm{b}}$ & $244^{\mathrm{a}}$ & 24.37 & 0.005 & 0.004 & $<0.001$ \\
\hline trans-12,trans- 14 & $2 \cdot 47$ & 3.77 & 1.70 & $10 \cdot 3$ & $42 \cdot 6$ & 4.00 & $3.49^{\mathrm{b}}$ & $89 \cdot 3^{\mathrm{a}}$ & $20.9^{b}$ & $5 \cdot 51^{\mathrm{b}}$ & $68 \cdot 2^{\mathrm{a}}$ & $101^{\mathrm{a}}$ & 7.765 & $<0.001$ & 0.004 & $<0.001$ \\
\hline trans -13 ,trans -15 & 1.46 & 3.76 & 0.78 & 2.42 & 3.05 & 0.86 & $1.90^{\mathrm{b}}$ & $8 \cdot 15^{\mathrm{a}}$ & $1.05^{\mathrm{b}}$ & $8 \cdot 87^{a, b}$ & $12 \cdot 4^{\mathrm{a}}$ & $3.54^{\mathrm{b}}$ & 1.056 & 0.001 & 0.006 & 0.052 \\
\hline
\end{tabular}

a,b,c Mean values within a row for each incubation time with unlike superscript letters were significantly different $(P<0.05)$.

* Incubations established in $100-\mathrm{ml}$ flasks containing $400 \mathrm{ml}$ ground dried hay and $50 \mathrm{ml}$ of diluted rumen fluid maintained at $39^{\circ} \mathrm{C}$ under carbon dioxide containing no additional $\alpha$-linolenic acid (CON) or $5 \mathrm{mg}$ of added $a$-linolenic acid and rumen fluid with de-ionised $\mathrm{H}_{2} \mathrm{O}$ or $\mathrm{D}_{2} \mathrm{O}$.

$\dagger$ Significance due to incubation time, incubation treatment and their interaction.

‡ SEM for $n 36$ measurements.

Table 4. Enrichment of $n+1, n+2$ and $n+3$ isotopomers of 18:2 intermediates formed during incubations of $a$-linolenic acid (ALA) with strained rumen contents and ${ }^{2} \mathrm{H}$-containing buffer ${ }^{*}$ (Mean values with their pooled standard errors)

\begin{tabular}{|c|c|c|c|c|c|c|c|c|c|c|c|c|c|c|c|c|c|c|}
\hline \multirow[b]{3}{*}{ Incubation time (h)... } & \multicolumn{15}{|c|}{ Isotopomers } & & & \\
\hline & \multicolumn{5}{|c|}{$n+1$} & \multicolumn{5}{|c|}{$n+2$} & \multicolumn{5}{|c|}{$n+3$} & \multicolumn{3}{|c|}{$P \dagger$} \\
\hline & 0 & 1.5 & 3 & 12 & SEM $\ddagger$ & 0 & 1.5 & 3 & 12 & SEM $\ddagger$ & 0 & 1.5 & 3 & 12 & SEM $¥$ & $n+1$ & $n+2$ & $n+3$ \\
\hline \multicolumn{19}{|l|}{ Fatty acid } \\
\hline cis-12, cis-15-18:2 & $-0.05^{\mathrm{b}}$ & $1 \cdot 12^{\mathrm{a}}$ & $1 \cdot 13^{\mathrm{a}}$ & $1.14^{\mathrm{a}}$ & 0.024 & $0.05^{\mathrm{b}}$ & $0.96^{\mathrm{a}}$ & $1.01^{\mathrm{a}}$ & $1.00^{\mathrm{a}}$ & 0.012 & $0.05^{\mathrm{b}}$ & $0.38^{\mathrm{a}}$ & $0.39^{\mathrm{a}}$ & $0.53^{\mathrm{a}}$ & 0.066 & $<0.001$ & $<0.001$ & $<0.001$ \\
\hline trans-10, cis-15-18:2 & ND & ND & 1.00 & 1.06 & 0.057 & ND & ND & $0.70^{\mathrm{b}}$ & $0.80^{\mathrm{a}}$ & 0.045 & ND & ND & 0.15 & 0.19 & 0.070 & 0.234 & 0.042 & 0.474 \\
\hline trans-11,cis-15-18:2 & $0.49^{b}$ & $1.04^{\mathrm{a}}$ & $1.02^{\mathrm{a}}$ & $0.97^{\mathrm{a}}$ & 0.022 & $0.32^{\mathrm{c}}$ & $0.78^{\mathrm{a}}$ & $0.75^{\mathrm{a}}$ & $0.68^{\mathrm{b}}$ & 0.017 & 0.05 & 0.12 & 0.12 & 0.15 & 0.038 & $<0.001$ & $<0.001$ & 0.165 \\
\hline cis-9, trans-11-18:2 & $0.33^{a}$ & $0.20^{\mathrm{b}}$ & $0.26^{b}$ & $0.07^{\mathrm{C}}$ & 0.021 & -0.01 & -0.01 & -0.00 & -0.01 & 0.007 & -0.01 & -0.01 & -0.01 & -0.01 & 0.002 & $<0.001$ & 0.327 & 0.818 \\
\hline trans-10,cis-12-18:2 & $-0.02^{\mathrm{C}}$ & $0.04^{\mathrm{b}}$ & $0.13^{\mathrm{a}}$ & $0.05^{\mathrm{b}}$ & 0.018 & $0.01^{\mathrm{a}}$ & $-0.05^{b}$ & $-0.08^{\mathrm{b}}$ & $-0.06^{b}$ & 0.011 & ND & ND & ND & ND & ND & $<0.001$ & $<0.001$ & - \\
\hline trans-11, cis-13-18:2 & $0.04^{\mathrm{c}}$ & $0.99^{a}$ & $1.00^{a}$ & $0.69^{b}$ & 0.020 & $0.01^{\mathrm{c}}$ & $0.72^{\mathrm{a}}$ & $0.72^{\mathrm{a}}$ & $0.47^{\mathrm{b}}$ & 0.024 & 0.01 & -0.02 & 0.06 & 0.10 & 0.056 & $<0.001$ & $<0.001$ & 0.259 \\
\hline trans-11,trans-13-18:2 & $0.26^{c}$ & $0.70^{\mathrm{b}}$ & $0.86^{\mathrm{a}}$ & $0.93^{\mathrm{a}}$ & 0.035 & $0.05^{\mathrm{d}}$ & $0.33^{\mathrm{c}}$ & $0.45^{\mathrm{b}}$ & $0.62^{\mathrm{a}}$ & 0.023 & $-0.00^{c}$ & $0.08^{b}$ & $0.09^{b}$ & $0.30^{\mathrm{a}}$ & 0.022 & $<0.001$ & $<0.001$ & $<0.001$ \\
\hline trans-12, trans-14-18:2 & $0.27^{c}$ & $0.55^{\mathrm{b}}$ & $0.92^{\mathrm{a}}$ & $1.08^{\mathrm{a}}$ & 0.057 & $0.00^{\mathrm{d}}$ & $0.16^{\mathrm{C}}$ & $0.79^{b}$ & $1.03^{\mathrm{a}}$ & 0.030 & $0.01^{\mathrm{C}}$ & $0.03^{\mathrm{C}}$ & $0.42^{b}$ & $0.61^{a}$ & 0.016 & $<0.001$ & $<0.001$ & $<0.001$ \\
\hline
\end{tabular}

a,b,c Mean values within a row for each incubation time with unlike superscript letters were significantly different $(P<0.05)$

* Enrichment calculated from the ratio of moles per cent excess (MPE) in the incubation product/MPE in water. Mean $56 \cdot 6$ (SE 1.33) \% MPE enrichment in deuterated water. Natural abundance of $n+1, n+2$ and $n+3$ isotopomers was determined for the same products formed during incubations of ALA with strained rumen contents diluted in de-ionised water.

† Significance due to incubation time.

$\ddagger$ Pooled SEM for $n 12$ measurements. 

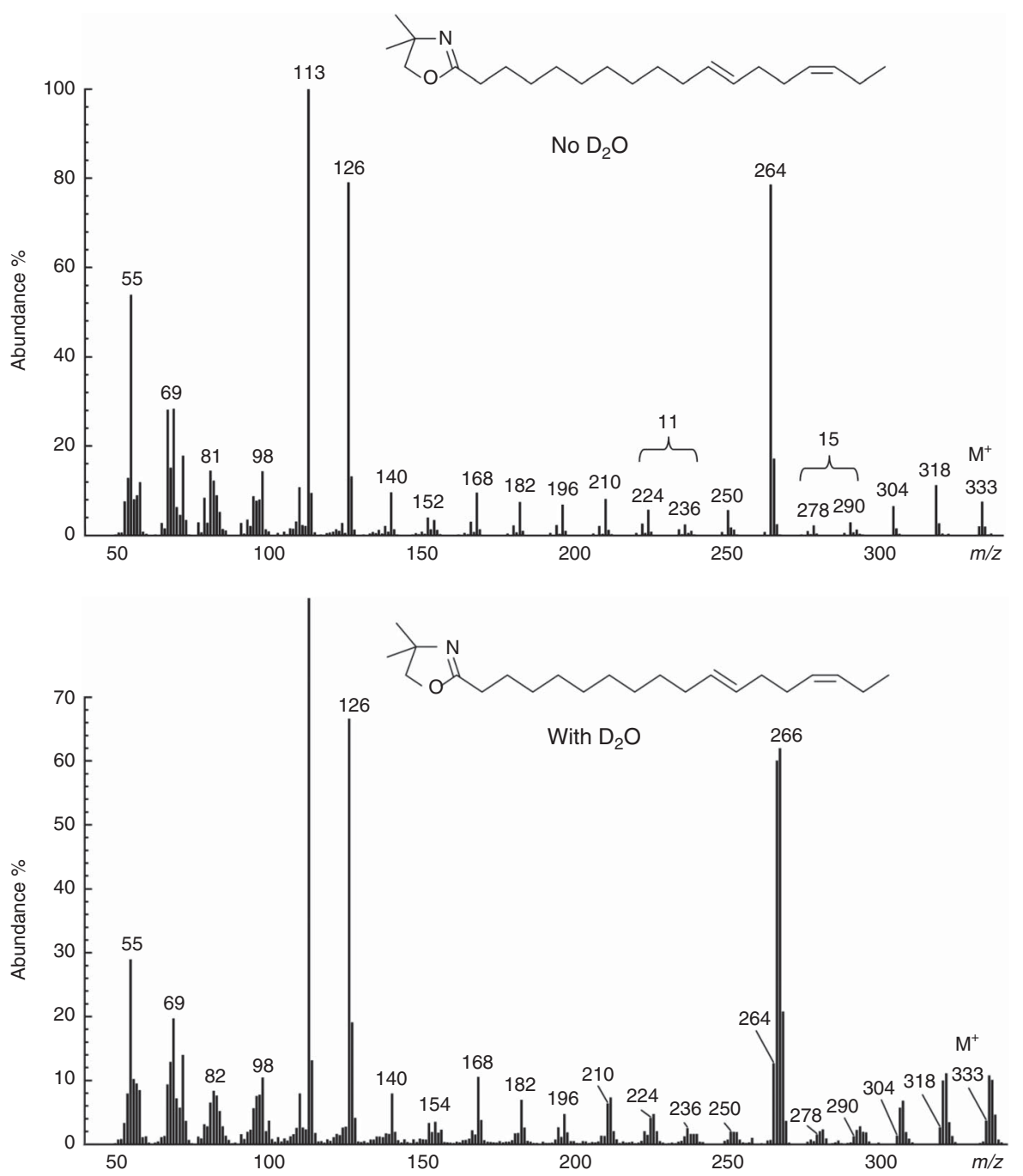

Fig. 4. Mass spectrum of the 4,4-dimethyloxazoline derivative of trans-11,cis-15-18:2 formed from $a$-linolenic acid during incubations with strained rumen contents diluted with buffer prepared using de-ionised water or deuterium oxide. An abundant ion at $\mathrm{m} / \mathrm{z} 264$ along with gaps of 12 atomic mass units between $\mathrm{m} / \mathrm{z} 224$ and 236 and 278 and 290 confirmed a $\Delta 11,15$ double-bond arrangement. Enrichment of ion fragments at $m / z 210$ and $211(n+1)$ and 264 and $266(n+2)$ indicated labelling on $\mathrm{C}-9$ and $\mathrm{C}-13$ of the fatty acid moiety during incubations with ${ }^{2} \mathrm{H}$-containing buffer.

flask contents were too low to obtain reliable MS spectra. Mass spectra of the methyl esters of trans-11,cis-13-CLA and trans-11, trans-13-CLA revealed a molecular ion at $m / z 296(n+2)$, indicating that both intermediates formed from ALA during incubations with $\mathrm{D}_{2} \mathrm{O}$ contained two ${ }^{2} \mathrm{H}$ labels. The mass spectrum of the DMOX derivative of trans-11,trans-13-CLA (Fig. 5) indicated enrichment in ion fragments at $m / z 334$ and 335 ( $n+1$ and $n+2$, respectively), confirming the incorporation of two or more ${ }^{2} \mathrm{H}$ atoms. An increase in ion fragment isotopes at $m / z 211(n+1)$ and $m / z 306(n+2)$ suggested labelling at C-9 and $\mathrm{C}-16$, respectively. However, during the course of incubations with $\mathrm{D}_{2} \mathrm{O}$, the abundance of the ion fragment at $\mathrm{m} /$ $z 336(n+3)$ increased, which along with enrichment of $n+2$ isotopomers with $m / z<306$ suggested that another ${ }^{2} \mathrm{H}$ label was incorporated between $\mathrm{C}-9$ and $\mathrm{C}-16$. The mass spectrum of the DMOX derivative of trans-12,trans-14-CLA revealed a molecular ion at $m / z 336$ (data not presented), indicating incorporation of three ${ }^{2} \mathrm{H}$ atoms, but the locations could not be established.
Formation of octadecenoic acids, oxygenated fatty acids and stearic acid during incubation of $\alpha$-linolenic acid with strained rumen contents

A mixture of trans-4 to trans-16-18: 1 and cis-9 to cis-16-18: 1 accumulated during incubations with ALA. Trans-11,-13,-14,-15 and -16-18: 1 and cis-15-18:1 represented the most abundant octadecenoic intermediates. Owing to extensive labelling during incubations with $\mathrm{D}_{2} \mathrm{O}$, none of the $18: 1$ isomers could be resolved during GC analysis, preventing the amounts synthesised and enrichment patterns to be accurately determined. Nevertheless, the mass spectrum of the DMOX derivative of trans-11-18:1 indicated the incorporation of ${ }^{2} \mathrm{H}$ atoms on C-9, C-13 and C-15 of the FA moiety (data not presented).

Incubations with ALA also resulted in the formation of 9-O-18:0, 10-O-18:0 and 13-O-18:0, none of which was labelled after $12 \mathrm{~h}$ (data not presented). For all incubations, 18:0 was the end product containing multiple ${ }^{2} \mathrm{H}$ labels. 

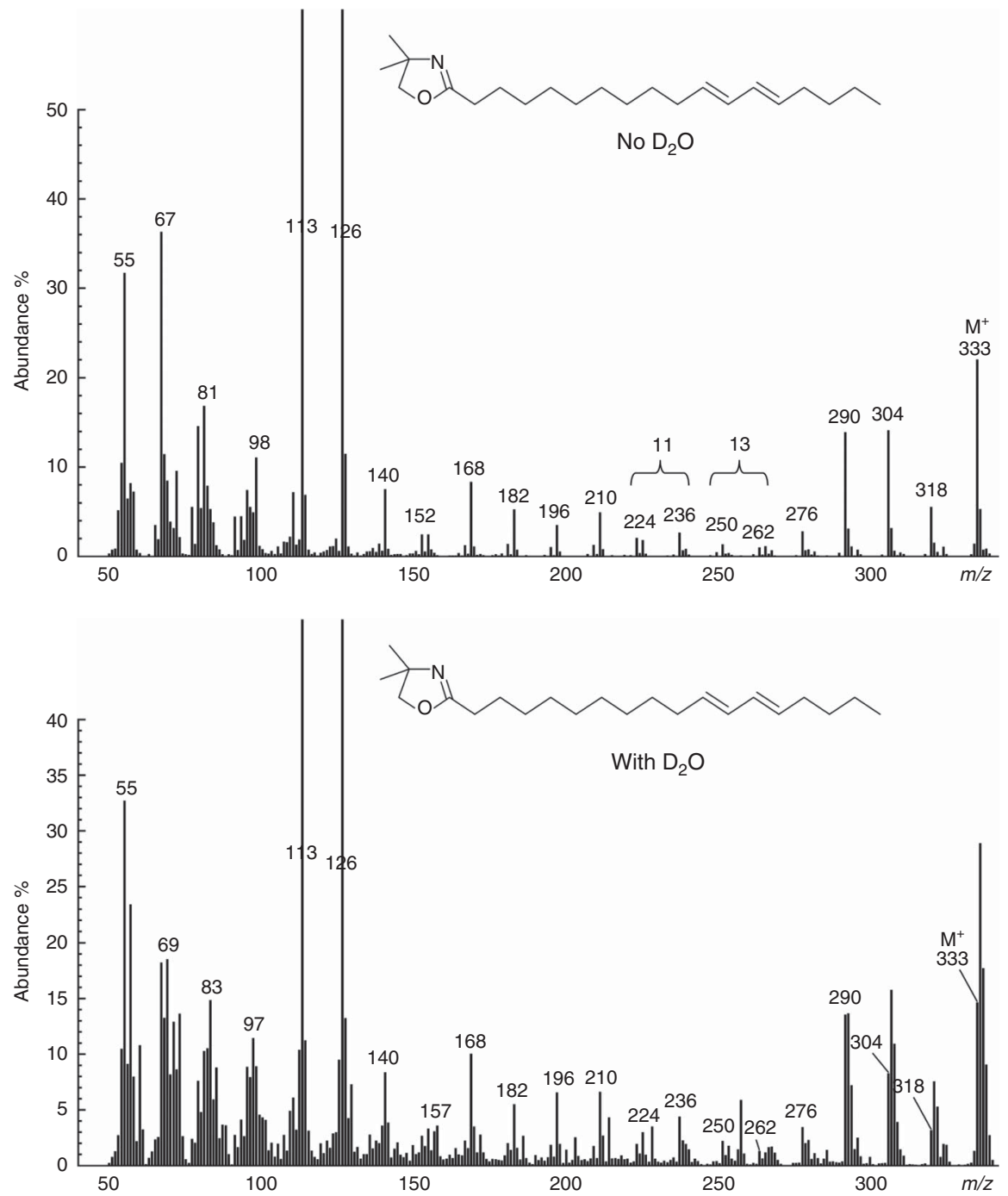

Fig. 5. Mass spectrum of the 4,4-dimethyloxazoline derivative of trans-11,trans-13-18:2 from $a$-linolenic acid during incubations with strained rumen contents diluted with buffer prepared using de-ionised water or deuterium oxide. Gaps of 12 atomic mass units between $\mathrm{m} / \mathrm{z} 224$ and 236 and 250 and 262 located double bonds at $\Delta 11$ and 13, respectively. Enrichment of ion fragments at $m / z 210$ and $211(n+1)$ and 304 and $306(n+2)$ provide tentative evidence of labelling on C-9 and C-16 of the fatty acid moiety during incubations with ${ }^{2} \mathrm{H}$-containing buffer.

The molecular ion of the DMOX derivative of $18: 0$ at $\mathrm{m} / z 342$ $(337+5)$ indicated that up to five ${ }^{2} \mathrm{H}$ atoms were incorporated during the reduction of ALA to 18:0, but the locations could not be determined.

\section{Discussion}

Most reports based on incubations with ruminal digesta ${ }^{(23)}$ or pure cultures of rumen bacteria ${ }^{(38)}$ indicate that biohydrogenation of ALA is initiated by isomerisation of the cis-12 double bond to yield a cis-9,trans-11,cis-15-CLN intermediate catalysed by a 12-cis,11-trans isomerase ${ }^{(26)}$. Alternative pathways of ALA biohydrogenation have been proposed $^{(9,23-25)}$, but the mechanisms and products formed are not known. In the present investigation, incubations of ALA with ruminal contents were made with or without $\mathrm{D}_{2} \mathrm{O}$ to better understand the fate of ALA in the rumen. Control incubations were also performed, allowing identification of products formed from ALA during incubations with strained rumen contents. The non-ionic surfactant Tween 80 was used to disperse ALA that has been shown to result in more extensive biohydrogenation during incubations with rumen contents compared with sonication or dissolving substrates in ethanol ${ }^{(39)}$. Incubations with rumen contents diluted with water or $\mathrm{D}_{2} \mathrm{O}$ resulted in the appearance of similar products, but the rate of added ALA disappearance and reaction kinetics were slower in the presence of the ${ }^{2} \mathrm{H}$ isotope.

Cis-9,trans-11,cis-15-CLN was the major product synthesised from ALA, but trans-9,trans-11,cis-15-CLN was also detected. Both $\Delta 9,11,15$-CLN products formed during incubations of ALA with $\mathrm{D}_{2} \mathrm{O}$ were labelled on C-13. Enrichment of the $n+1$ isotopomer of cis-9,trans-11,cis-15-CLN was greatest immediately after the addition of ALA. Incorporation of the ${ }^{2} \mathrm{H}$ label in trans-9,trans-11,cis-15-CLN was consistent across all incubation times. Labelling of geometric 9,11,15-CLN isomers is analogous 
to the incorporation of ${ }^{2} \mathrm{H}$ in 9,11-CLA formed during incubations of LA with $\mathrm{D}_{2} \mathrm{O}$ and pure cultures of Butyrivibrio fibrisolvens $^{(15,38,40)}$, Bifidobacterium breve and Propionibacterium freudenreichii subsp. shermanii DSM $4902 \mathrm{~T}^{(41)}$, ovine rumen contents ${ }^{(15)}$ or human mixed faecal bacteria ${ }^{(41)}$. The appearance of a single label on C-13 of 9,11-CLA isomers was explained by $\mathrm{H}$ abstraction on $\mathrm{C}-11$, which for reasons of thermodynamic stability was followed by re-arrangement of the double bond and the assimilation of a proton from water $^{(15,38,41)}$. Abstraction of a single $\mathrm{H}$ at C-11 and formation of a radical intermediate would also explain an increase in $n+1$ isotopomers and the labelling pattern of 9,11,15-CLN isomers formed from ALA. The cis-9,trans-11,cis-15-CLN isomer was formed in much higher amounts than trans-9,trans-11,cis-15CLN, which may be related to possible differences in the thermodynamics of these reactions.

A common mechanism for the synthesis of $\Delta 9,11$-CLA from LA and $\Delta 9,11,15$-CLN from ALA during incubations with mixed rumen microbiota is not unexpected, given that the same 12-cis,11-trans isomerase isolated from B. fibrisolvens is capable of both reactions ${ }^{(40)}$. Functional studies of the $\Delta^{12}$-cis$\Delta^{11}$-trans-isomerase isolated from $B$. fibrisolvens ${ }^{(38)}$ suggest that the reaction is initiated by $\pi$ electrons of C-9 double bond interacting with the hydrophobic binding site of the enzyme ${ }^{(40)}$. Other bacteria are capable of converting ALA to CLN isomers in vitro. Lactobacillus plantarum AKU 1009a catalyses the synthesis of cis-9,trans-11,cis-15-CLN and trans-9,trans-11,cis15-CLN from ALA ${ }^{(42,43)}$. Geometric isomers of 9,11,15-CLN are also formed during incubations of ALA with strains of Bifidobacterium $^{(44-46)}$ and Propionibacterium ${ }^{(46)}$. It remains unclear as to whether the mechanisms of 9,11,15-CLN synthesis from ALA are common to both food-producing bacterial strains and ruminal bacteria.

Incubations of ALA with rumen contents resulted in the formation of trans-9,trans-11,cis-13-CLN. Enrichment of the $n+1$ isotopomer of trans-9,trans-11,cis-13-CLN increased over the course of $12-\mathrm{h}$ incubations, but was consistently lower compared with incorporation of ${ }^{2} \mathrm{H}$ in $\Delta 9,11,15$-CLN products (average $0 \cdot 20$ and $0 \cdot 81$, respectively). However, the labelling pattern of trans-9,trans-11,cis-13-CLN was inconclusive. Nevertheless, an increase in the abundance of the $n+1$ isotopomer above natural enrichment suggests that the conversion of trans-9,trans-11, cis-13-CLN from ALA involves an exchange of $\mathrm{H}$ with water, by a mechanism that apparently differs from $\Delta 9,11,15$-CLN formation. The isomerase isolated from Propionibacterium acnes is capable of converting ALA to CLN isomers with trans-11,trans-13,cis-15-CLN as the main product with trace amounts of trans-10, cis-12, cis-15-CLN also being formed ${ }^{(47)}$. Incubation of ALA with rumen contents resulted in the formation of $\Delta 10,12,15$-CLN but in amounts too low to conclude about the possible mechanisms responsible.

Incubations of ALA with rumen contents also resulted in the formation of cis-7,cis-12,cis-15-18:3 and $\Delta 8,12,15-18: 3$ isomers. Assignment of double-bond geometry of these products based on GC retention times would require further validation based on NMR or reductive ozonolysis. In earlier investigations, complementary $\mathrm{Ag}^{+}$-TLC and GC-MS analysis identified cis-5,cis-12-18:2, cis-6,cis-12-18:2, cis-7,cis-12-18:2, cis-8,cis-12-18: 2 and trans-8,cis-12-18: 2 as intermediates of LA metabolism during incubations with ruminal digesta ${ }^{(16)}$. The appearance of the 18:3 intermediates containing a cis-12 and cis-15 double-bond arrangement provides the first evidence that transformation of ALA may also involve migration of the cis-9 double bond. Enrichment in $n+1$ isotopomers of $\Delta 7,12,15-18: 3$ and $\Delta 8,12,15-18: 3$ during incubations of ALA with $\mathrm{D}_{2} \mathrm{O}$ did not differ from natural enrichment, indicating that formation of these products does not involve $\mathrm{H}$ exchange with water. Cis-trans isomerisation of doubly deuterated cis-9-18:1 to trans-9-18: 1 does not result in the loss of ${ }^{2} \mathrm{H}^{(48)}$. Thus, an absence of labelling confirms that formation of $\Delta 7,12,15-18: 3$ and $\Delta 8,12,15-18: 3$ from ALA does not involve prior formation of $\Delta 9,11,13$-CLN or $\Delta 9,11,15$-CLN. It is not possible to conclude on whether double-bond migration is catalysed by a cis-trans isomerase or via an alternative series of reactions, however. Hydrogenation of LA with iridium, palladium and ruthenium catalysts is known to generate trans-8,cis-12$18: 2$ and cis-9,trans-13-18:2 with cis-8,cis-12-18:2 and cis-9, cis-13-18:2 predicted as minor products ${ }^{(49)}$. Under these circumstances, double-bond migration has been explained by the release of the $\mathrm{H}$ atom from the adjacent methylene group at $\Delta 8$ or $\Delta 14$ of the semi-hydrogenated $\mathrm{C}-\mathrm{C}$ bond and subsequent rotation of the $\mathrm{C}-\mathrm{C}$ bond during abstraction of the $\mathrm{H}$ atom ${ }^{(49)}$. Further investigations involving incubations of ALA with living and irradiated rumen contents would be required to establish whether a cis-trans isomerase or non-enzymatic reaction catalyses re-arrangement of the cis-9 double bond.

Trans-11,cis-15-18:2 was the major 18:2 product formed from ALA, consistent with the established pathway of ALA biohydrogenation ${ }^{(22-25,27)}$. The $n+2$ isotopomer of trans-11,cis-15-18 : 2 during incubations of ALA with $\mathrm{D}_{2} \mathrm{O}$ were highly enriched after $1.5 \mathrm{~h}$ of incubation with single ${ }^{2} \mathrm{H}$ labels incorporated on C-9 and C-13. The labelling pattern is consistent with $\Delta 11,15-18: 2$ intermediates being formed from $\Delta 9,11,15$-CLN labelled on C-13, with reduction of the cis-9 double bond involving $\mathrm{H}$ abstraction on $\mathrm{C}-10$ and incorporation of a single $\mathrm{H}$ from water on C-9. Previous experiments have shown that the reduction of cis-9,trans-11-18:2 to trans-11-18: 1 results in labelling on C-9 during incubations of $\mathrm{LA}$ and $\mathrm{D}_{2} \mathrm{O}$ with ruminal digesta ${ }^{(15)}$ or human intestinal bacteria $^{(41)}$.

Under routine GC analysis with a polar 100-m capillary column, trans-10,cis-15-18:2 and trans-11,cis-15-18:2 elute as a single peak that can only be separated using a $100-\mathrm{m}$ GC column with an ionic liquid stationary phase $e^{(32)}$ or $\mathrm{Ag}^{+}$ solid-phase extraction and semi-preparative HPLC ${ }^{(50)}$. Re-analysis of FAME in the present study using the SLB-IL111 column provided confirmation that trans-10,cis-15-18:2 is formed from ALA. An increase in the $n+2$ isotopomer indicates that transformation of ALA to trans-10,cis-15-18:2 by rumen microbiota involves exchange of two $\mathrm{H}$ ions from water. It has been suggested that trans-10,cis-15-18:2 is a product formed from the reduction of trans-10,cis-12,cis-15-CLN in the rumen ${ }^{(25,32)}$. Even though enrichment of $n+1$ isotopomers of $\triangle 10,12,15$-CLN was detected during incubations of ALA with $\mathrm{D}_{2} \mathrm{O}$, the labelling pattern of the trans-10,cis-15-18:2 product was inconclusive. L. plantarum AKU 1009a is capable of 
converting ALA to trans-10,cis-15-18:2 via the formation of cis-9,trans-11,cis-15-18:3 and trans-9,trans-11,cis-15-18:3 as intermediates ${ }^{(43)}$. It is not clear whether the same transformation also occurs in the rumen.

Incubations of ALA with rumen contents also resulted in the formation of cis-12,cis-15-18:2. The $n+1, n+2$ and $n+3$ isotopomers of cis-12,cis-15-18:2 were progressively enriched during incubations of ALA with $\mathrm{D}_{2} \mathrm{O}$, but the position of ${ }^{2} \mathrm{H}$ labels could not be located. It is possible that cis-12,cis-15-18:2 originates from the reduction of cis-7,cis-12,cis-15-18:3 or $\Delta 8,12,15-18: 3$ or from the direct reduction of ALA. However, the increase in the $n+3$ isotopomer of cis-12,cis-15-18:2 suggests that an alternative mechanism may be responsible. All incubations contained LA, but the amounts did not increase following ALA addition. No enrichment in $n+1, n+2$ or $n+3$ isotopomers was detected over the course of incubations with $\mathrm{D}_{2} \mathrm{O}$, indicating that ALA is not converted to LA by rumen microbiota.

The major pathways of ALA biohydrogenation do not consider isomers of CLA as intermediates. In the present investigation, small amounts of trans-11,cis-13-CLA, trans-11, trans-13-CLA and trans-12,trans-14-CLA were formed from ALA. Enrichment of $n+2$ isotopomers indicates that formation of $\Delta 11,13$-CLA involves an exchange of $\mathrm{H}$ with water. The mass spectrum of the DMOX derivative was difficult to interpret but provided some indications of labelling on C-9 and C-16. Over the course of 12-h incubations, an increase in the enrichment of $n+3$ isotopomers was detected, indicating that the formation of trans-11,trans-13-CLA involved the incorporation of another ${ }^{2} \mathrm{H}$ label, but the location could not be established with a high degree of certainty. Earlier studies have shown that formation of cis-9,trans-11-CLA from LA results in labelling on $\mathrm{C}-13^{(15)}$. Further reduction of cis-9,trans-11-CLA to trans-11-18:1 results in the incorporation of ${ }^{2} \mathrm{H}$ on $\mathrm{C}-9^{(41)}$. Assuming that the same mechanisms are also involved in transforming CLN products to CLA, then labelling on C-9 would be expected if $\Delta 11,13$-CLA is formed by the reduction of $\Delta 9,11,13$-CLN. Given the uncertainties in the labelling pattern, it was not possible to confirm $\Delta 9,11,15$-CLN as a precursor for $\Delta 11,13$-CLA formation or recent reports that strains of $B$. fibrisolvens convert trans-11,cis-15-18: 2 to trans-11, cis-13-CLA ${ }^{(51)}$. Much earlier investigations reported that cis-9,trans-11,cis-13-CLN is hydrogenated to trans-11-18:1, which in the presence of $\mathrm{D}_{2} \mathrm{O}$ resulted in labelling at C-9, C-10, C-13 and C-14, whereas cis-9, trans-11,trans-13-CLN was not hydrogenated ${ }^{(52)}$

Mechanisms explaining the transformation of ALA to trans-12,trans-14-CLA are not resolved from the present investigation. An increase in the $n+3$ isotopomer of trans-12, trans-14-CLA was detected after $12 \mathrm{~h}$ of incubation with ALA, but the labelling pattern was not informative. A possible explanation is that trans-12,trans-14-CLA is formed from the isomerisation of trans-11,cis-15-18:2 or geometric isomers of 11,13-CLA by a mechanism that involves an exchange of $\mathrm{H}$ with water. Earlier investigations with ${ }^{13} \mathrm{C}$-labelled ALA reported significant ${ }^{13} \mathrm{C}$ enrichment in $\Delta 8,10$-CLA, $\Delta 9,11$-CLA, $\Delta 10,12$ CLA and $\Delta 11,13$-CLA intermediates, suggesting that multiple CLA isomers are formed from ALA during incubations with rumen contents ${ }^{(26)}$. Earlier studies have reported formation of
trans-11,trans-13-CLA and cis-11,trans-13-CLA from ALA ${ }^{(27)}$. In the present study, addition of ALA did not increase $\Delta 8,10$-CLA, $\Delta 9,11$-CLA or $\Delta 10,12$-CLA formation and or enrich cis-9,trans-11-18:2 at $n+2$. This would exclude ALA being transformed to CLA products other than geometric isomers of $\Delta 11,13$ and $\Delta 12,14$-CLA in the rumen.

Multiple 18:1 isomers accumulated during incubations of ALA with rumen contents. It was not possible to resolve all 18:1 isomers during GC and GC-MS analysis because of the broad peak shapes of isomers containing multiple ${ }^{2} \mathrm{H}$ labels. However, cis-12-18:1, cis-15-18:1, trans-11-18:1, trans-12-18:1, trans-13-18: 1, trans-14-18:1, trans-15-18: 1 and trans-16-18:1 were detected in flask contents during incubations of ALA with and without $\mathrm{D}_{2} \mathrm{O}$. The mass spectrum of the DMOX derivative of trans-11-18:1 indicated the incorporation of ${ }^{2} \mathrm{H}$ atoms on C-9, C-13 and C-15, consistent with this isomer originating from the sequential reduction of cis-9,trans-11,cis-15-CLN (labelled on C-13) and trans-11,cis-15-18: 2 (labelled on C-9 and C-13), with the reduction of the cis- 15 double bond being associated with the assimilation of ${ }^{2} \mathrm{H}$ on $\mathrm{C}-15$. In all incubations, 18: 0 was detected as the major end product of ALA biohydrogenation, which was found to contain up to five ${ }^{2} \mathrm{H}$ labels.

Overall, incubations of physiological amounts of ALA with strained rumen contents offer an explanation for the appearance of cis-9,trans-11,trans-15-CLN, $\Delta 9,11,13-\mathrm{CLN}$, trans-11,trans-13-18:2, trans-12,trans-14-18:2, trans-10,cis15-18: 2, trans-11,cis-15-18: 2 and cis-12,cis-15-18:2 in bovine muscle $^{(7,53)}$, adipose ${ }^{(50,53)}$ and milk fat ${ }^{(8,54)}$. Data from this and earlier investigations indicate that the abundance of specific FA containing one or more trans double bonds can be expected to be higher in meat or milk from ruminants fed diets rich in ALA, but the implications on the health of human consumers are, however, uncertain.

\section{Conclusions}

Incubations of ALA with rumen contents with or without $\mathrm{D}_{2} \mathrm{O}$ indicated that biohydrogenation proceeds via several distinct mechanisms leading to the formation of a diverse range of intermediates, many of which have not been characterised previously. Products formed by alternative metabolic pathways were quantitatively less important than the established intermediates of ALA biohydrogenation in the rumen. The complexity of the ruminal microbiota may account for a large part of the diversity of such reactions. Other than for the main routes of ALA metabolism, we have little knowledge of which microbial species might catalyse the different reactions.

\section{Acknowledgements}

The authors gratefully acknowledge and appreciate the technical assistance of Minna Aalto (Natural Resources Institute Finland) during lipid analysis.

This study was supported in part by core funding from the Finnish Ministry of Agriculture and Forestry, the Scottish Government Rural and Environment Science and Analytical Services Division and a $\mathrm{PhD}$ studentship from the Raisio Science 
Foundation and the August Johannes and Aino Tiura Agricultural Science Foundations (awarded to A. M. H.). None of the funders had any role in the experimental design, data analysis or writing of this article.

The authors' contributions are as follows: A. M. H. and K. J. S. designed the study; A. M. H. completed the in vitro incubations; A. M. H., H. L., R. J. W., N. M., V. T. and K. J. S. contributed to the analysis of lipids, determination of ${ }^{2} \mathrm{H}$ enrichment and FA identification; A. M. H. analysed the data under the supervision of R. J. W. and K. J. S.; A. M. H. and K. J. S. wrote the manuscript; R. J. W., N. M. and H. L. provided advice and critically reviewed the manuscript. All the authors have read and approved the manuscript content.

There are no conflicts of interest.

\section{Supplementary material}

For supplementary material/s referred to in this article, please visit http://dx.doi.org/doi:10.1017/S0007114516001446

\section{References}

1. Wahle KWJ, Heys SD \& Rotondo D (2004) Conjugated linoleic acids: are they beneficial or detrimental to health? Prog Lipid Res 43, 553-587.

2. Benjamin S \& Spener F (2009) Conjugated linoleic acids as functional food: an insight into their health benefits. Nutr Metab (Lond) 6, 36.

3. Koba K \& Yanagita T (2011) Potential health benefits of pomegranate (Punica granatum) seed oil containing conjugated linolenic acid. In Nuts and Seeds in Health and Disease Prevention, pp. 919-924 [VR Preedy, R Watson and VB Patel, editors]. San Diego, CA: Academic Press.

4. Hennessy AA, Ross RP, Devery R, et al. (2011) The health promoting properties of the conjugated isomers of $\alpha$-linolenic acid. Lipids 46, 105-119.

5. Bassaganya-Riera J, Guri AJ \& Hontecillas R (2011) Treatment of obesity-related complications with novel classes of naturally occurring PPAR agonists. $J$ Obes 2011, 1-7.

6. Koba K, Belury MA \& Sugano M (2007) Potential health benefits of conjugated trienoic acids. Lipid Technol 19, 200-203.

7. Plourde M, Destaillats F, Chouinard PY, et al. (2007) Conjugated $\alpha$-linolenic acid isomers in bovine milk and muscle. J Dairy Sci 90, 5269-5275.

8. Lerch S, Shingfield KJ, Ferlay A, et al. (2012) Rapeseed or linseed in grass-based diets: effects on conjugated linoleic and conjugated linolenic acid isomers in milk fat from Holstein cows over 2 consecutive lactations. J Dairy Sci 95, 7269-7287.

9. Gómez-Cortés P, Tyburczy C, Brenna JT, et al. (2009) Characterization of cis-9 trans-11 trans-15 C18:3 in milk fat by GC and covalent adduct chemical ionization tandem MS. J Lipid Res 50, 2412-2420.

10. Hopkins C \& Chisholm MJ (1968) A survey of the conjugated fatty acids of seed oils. J Am Oil Chem Soc 45, 176-182.

11. Igarashi M \& Miyazawa T (2000) Newly recognized cytotoxic effect of conjugated trienoic fatty acids on cultured human tumor cells. Cancer Lett 148, 173-179.

12. Parodi P (1977) Conjugated octadecadienoic acids of milk fat. J Dairy Sci 60, 1550-1553.

13. Chin SF, Liu W, Storkson JM, et al. (1992) Dietary sources of conjugated dienoic isomers of linoleic acid, a newly recognized class of anticarcinogens. J Food Comp Anal 5, 185-197.
14. Palmquist DL, Lock AL, Shingfield KJ, et al. (2005) Biosynthesis of conjugated linoleic acid in ruminants and humans. Adv Food Nutr Res 50, 179-217.

15. Wallace RJ, McKain N, Shingfield KJ, et al. (2007) Isomers of conjugated linoleic acids are synthesized via different mechanisms in ruminal digesta and bacteria. J Lipid Res $\mathbf{4 8}$, 2247-2254.

16. Honkanen AM, Griinari JM, Vanhatalo A, et al. (2012) Characterization of the disappearance and formation of biohydrogenation intermediates during incubations of linoleic acid with rumen fluid in vitro. J Dairy Sci 95, 1376-1394.

17. Loor JJ, Ueda K, Ferlay A, et al. (2004) Biohydrogenation, duodenal flow, and intestinal digestibility of trans fatty acids and conjugated linoleic acids in response to dietary forage: concentrate ratio and linseed oil in dairy cows. J Dairy Sci $\mathbf{8 7}$, $2472-2485$.

18. Doreau M, Laverroux S, Normand J, et al. (2009) Effect of linseed fed as rolled seeds, extruded seeds or oil on fatty acid rumen metabolism and intestinal digestibility in cows. Lipids 44, 53-62.

19. Shingfield KJ, Lee MRF, Humphries DJ, et al. (2011) Effect of linseed oil and fish oil alone or as an equal mixture on ruminal fatty acid metabolism in growing steers fed maize silage-based diets. J Anim Sci 89, 3728-3741.

20. Wilde P \& Dawson R (1966) The biohydrogenation of alpha-linoleic acid and oleic acid by rumen micro-organisms. Biochem J 98, 469-475.

21. Kellens MJ, Goderis HL \& Tobback PP (1986) Biohydrogenation of unsaturated fatty acids by a mixed culture of rumen microorganisms. Biotechnol Bioeng 28, 1268-1276.

22. Harfoot CG \& Hazlewood GP (1997) Lipid metabolism in the rumen. In The Rumen Microbial Ecosystem, pp. 382-426 [PN Hobson and CS Stewart, editors]. London: Chapman \& Hall.

23. Waşowska I, Maia MRG, Niedzwiedzka KM, et al. (2006) Influence of fish oil on ruminal biohydrogenation of C18 unsaturated fatty acids. BrJ Nutr 95, 1199-1211.

24. Destaillats F, Trottier JP, Galvez JMG, et al. (2005) Analysis of $\alpha$-linolenic acid biohydrogenation intermediates in milk fat with emphasis on conjugated linolenic acids. J Dairy Sci $\mathbf{8 8}$, 3231-3239.

25. Griinari JM \& Bauman DE (1999) Biosynthesis of conjugated linoleic acid and its incorporation into meat and milk in ruminants. In Advances in Conjugated Linoleic Acid Research, pp. 180-200 [MP Yurawecz, MM Mossoba, JKG Kramer, MW Pariza and GJ Nelson, editors]. Champaign, IL: AOCS Press.

26. Lee Y \& Jenkins TC (2011) Biohydrogenation of linolenic acid to stearic acid by the rumen microbial population yields multiple intermediate conjugated diene isomers. J Nutr $\mathbf{1 4 1}$, $1445-1450$.

27. Jouany J, Lassalas B, Doreau M, et al. (2007) Dynamic features of the rumen metabolism of linoleic acid, linolenic acid and linseed oil measured in vitro. Lipids 42, 351-360.

28. European Union (1986) Council Directive 86/609/EEC on the approximation of laws, regulations and administrative provisions of the member states regarding the protection of animals used for experimental and other scientific purposes. Off $J$ Eur Communities L358, 1-28.

29. Kairenius P, Toivonen V \& Shingfield KJ (2011) Identification and ruminal outflow of long-chain fatty acid biohydrogenation intermediates in cows fed diets containing fish oil. Lipids $\mathbf{4 6}$, 587-606.

30. Shingfield KJ, Ahvenjärvi S, Toivonen V, et al. (2003) Effect of dietary fish oil on biohydrogenation of fatty acids and milk fatty acid content in cows. Anim Sci 77, 165-179. 
31. Delmonte P, Fardin-Kia AR, Kramer JKG, et al. (2012) Evaluation of highly polar ionic liquid gas chromatographic column for the determination of the fatty acids in milk fat. J Chromatogr A 1233, 137-146.

32. Alves SP \& Bessa RJB (2014) The trans-10,cis-15 18:2: a missing intermediate of trans-10 shifted rumen biohydrogenation pathway? Lipids $\mathbf{4 9}, 527-541$.

33. Spitzer V (1996) Structure analysis of fatty acids by gas chromatography - low resolution electron impact mass spectrometry of their 4,4-dimethyloxazoline derivatives - a review. Prog Lipid Res 35, 387-408.

34. Christie WW (1998) Gas chromatography-mass spectrometry methods for structural analysis of fatty acids. Lipids 33, 343-353.

35. AOCS Lipid Library (2014) Mass spectrometry of fatty acids derivatives. http://lipidlibrary.aocs.org/Analysis/content. cfm?ItemNumber $=39466 \&$ navItemNumber $=19206$ (accessed January 2016).

36. Kramer JKG, Blackadar CB \& Zhou J (2002) Evaluation of two GC columns (60-m SUPELCOWAX 10 and 100-m CP Sil 88) for analysis of milkfat with emphasis on CLA, 18:1, 18:2 and 18:3 isomers, and short- and long-chain FA. Lipids 37, 823-835.

37. Campbell IM (1974) Incorporation and dilution values-their calculation in mass spectrally stable isotope labeling experiments. Bioorg Chem 3, 386-397.

38. Kepler CR \& Tove SB (1967) Biohydrogenation of polyunsaturated fatty acids III: purification and properties of a linoleate 12-cis,11-trans isomerase from Butyrivibrio fibrisolvens. J Biol Chem 242, 5686-5692.

39. Khiaosa-ard R, Leiber F \& Soliva C (2010) Methods of emulsifying linoleic acid in biohydrogenation studies in vitro may bias the resulting fatty acid profiles. Lipids 45, 651-657.

40. Kepler CR, Tucker WP \& Tove SB (1971) Biohydrogenation of unsaturated fatty acids. V. Stereospecificity of proton addition and mechanism of action of linoleic $\Delta^{12}$-cis, $\Delta^{11}$-trans-isomerase from Butyrivibrio fibrisolvens. J Biol Chem 246, 2765-2771.

41. McIntosh FM, Shingfield KJ, Devillard E, et al. (2009) Mechanism of conjugated linoleic acid and vaccenic acid formation in human faecal suspensions and pure cultures of intestinal bacteria. Microbiology 155, 285-294.

42. Kishino S, Ogawa J, Ando A, et al. (2003) Conjugated alphalinolenic acid production from alpha-linolenic acid by Lactobacillus plantarum AKU 1009a. Eur J Lipid Sci Technol 105, 572-577.

43. Kishino S, Ogawa J, Yokozeki K, et al. (2009) Metabolic diversity in biohydrogenation of polyunsaturated fatty acids by lactic acid bacteria involving conjugated fatty acid production. Appl Microbiol Biotechnol 84, 87-97.

44. Gorissen L, Raes K, Weckx S, et al. (2010) Production of conjugated linoleic acid and conjugated linolenic acid isomers by Bifidobacterium species. Appl Microbiol Biotechnol 87, 2257-2266.

45. Park HG, Cho HT, Song M, et al. (2012) Production of a conjugated fatty acid by Bifidobacterium breve LMC520 from $\alpha$-linolenic acid: conjugated linolenic acid (CLnA). J Agric Food Chem 60, 3204-3210.

46. Hennessy AA, Barrett E, Paul Ross R, et al. (2012) The production of conjugated $\alpha$-linolenic, $\gamma$-linolenic and stearidonic acids by strains of Bifidobacteria and Propionibacteria. Lipids 47, 313-327.

47. Hornung E, Krueger C, Pernstich C, et al. (2005) Production of (10E,12Z)-conjugated linoleic acid in yeast and tobacco seeds. Biochim Biophys Acta 1738, 105-114.

48. von Wallbrunn A, Richnow $\mathrm{HH}$, Neumann $\mathrm{G}$, et al. (2003) Mechanism of cis-trans isomerization of unsaturated fatty acids in Pseudomonas putida. J Bacteriol 185, $1730-1733$

49. Kitayama Y, Muraoka M, Takahashi M, et al. (1997) Catalytic hydrogenation of linoleic acid over platinumgroup metals supported on alumina. J Am Oil Chem Soc $\mathbf{7 4}$, $525-529$.

50. Turner TD, Meadus WJ, Mapiye C, et al. (2015) Isolation of $\alpha$-linolenic acid biohydrogenation products by combined silver ion solid phase extraction and semi-preparative high performance liquid chromatography. J Chromatogr B 980, 34-40.

51. Fukuda S, Nakanishi Y, Chikayama E, et al. (2009) Evaluation and characterization of bacterial metabolic dynamics with a novel profiling technique, real-time metabolotyping. PLoS ONE 4, e4893.

52. Rosenfled IS \& Tove SB (1971) Biohydrogenation of unsaturated fatty acids. VI. Source of hydrogen and stereospecificity of reduction. I Biol Chem 246, 5025-5030.

53. Nassu RT, Dugan MER, He ML, et al. (2011) The effects of feeding flaxseed to beef cows given forage based diets on fatty acids of longissimus thoracis muscle and backfat. Meat Sci 89, 469-477.

54. Kairenius P, Ärölä A, Leskinen H, et al. (2015) Dietary fish oil supplements depress milk fat yield and alter milk fatty acid composition in lactating cows fed grass silage-based diets. J Dairy Sci 98, 5653-5671. 